\title{
Efficacy of medium-chain fatty acid salts distilled from coconut oil against two enteric pathogen challenges in weanling piglets
}

Paola López-Colom, Lorena Castillejos ${ }^{1 *}$ (D), Agustina Rodríguez-Sorrento ${ }^{1}$, Mónica Puyalto², Juan José Mallo² and Susana María Martín-Orúe

\begin{abstract}
Background: The search for alternatives to antibiotics in pig production has increased the interest in natural resources with antimicrobial properties, such as medium-chain fatty acids (MCFA) as in-feed additives. This study evaluated the potential of a novel blend of MCFA salts (DIC) from distilled coconut oil with a lauric acid content to reduce enteropathogens and control intestinal diseases around weaning. Two experimental disease models were implemented in early-weaned piglets, consisting of two oral challenges: Salmonella Typhimurium $\left(1.2 \times 10^{8} \mathrm{CFU}\right)$ or enterotoxigenic Escherichia coli (ETEC) F4 $\left(1.5 \times 10^{9} \mathrm{CFU}\right)$. The parameters assessed were: animal performance, clinical signs, pathogen excretion, intestinal fermentation, immune-inflammatory response, and intestinal morphology.
\end{abstract}

Results: The Salmonella challenge promoted an acute course of diarrhea, with most of the parameters responding to the challenge, whereas the ETEC F4 challenge promoted a mild clinical course. A consistent antipathogenic effect of DIC was observed in both trials in the hindgut, with reductions in Salmonella spp. plate counts in the cecum ( $P=0.03$ ) on d 8 post-inoculation (PI) (Salmonella trial), and of enterobacteria and total coliform counts in the ileum and colon $(P<0.10)$ on d 8 PI (ETEC F4 trial). When analyzing the entire colonic microbiota (16S rRNA gene sequencing), this additive tended $(P=0.13)$ to reduce the Firmicutes/Bacteroidetes ratio and enriched Fibrobacteres after the Salmonella challenge. In the ETEC F4 challenge, DIC prompted structural changes in the ecosystem with increases in Dialister, and a trend $(P=0.14)$ to increase the Veillonellaceae family. Other parameters such as the intestinal fermentation products or serum pro-inflammatory mediators were not modified by DIC supplementation, nor were the histological parameters. Only the intraepithelial lymphocyte (IEL) counts were lowered by DIC in animals challenged with Salmonella $(P=0.07)$. With ETEC F4, the IEL counts were higher with $\mathrm{DIC}$ on $\mathrm{d} 8 \mathrm{PI}(P=0.08)$.

Conclusions: This study confirms the potential activity of this MCFA salts mixture to reduce intestinal colonization by opportunistic pathogens such as Salmonella or E. coli and its ability to modulate colonic microbiota. These changes could explain to some extent the local immune cell response at the ileal level.

Keywords: Enteric pathogen, Gut microbiota, Intestinal immunity, Medium-chain fatty acids, Weaning pig

\footnotetext{
*Correspondence: Iorena.castillejos@uab.cat

${ }^{1}$ Animal Nutrition and Welfare Service, Animal and Food Science

Department, Facultat de Veterinària, Universitat Autònoma de Barcelona, Bellaterra, Spain

Full list of author information is available at the end of the article
}

(c) The Author(s). 2019 Open Access This article is distributed under the terms of the Creative Commons Attribution 4.0 International License (http://creativecommons.org/licenses/by/4.0/) which permits unrestricted use, distribution, and reproduction in any medium, provided you give appropriate credit to the original author(s) and the source, provide a link to the Creative Commons license, and indicate if changes were made. The Creative Commons Public Domain Dedication waiver (http://creativecommons.org/publicdomain/zero/1.0/) applies to the data made available in this article, unless otherwise stated. 


\section{Background}

In modern pig production, early weaning around $4 \mathrm{wk}$ of life is associated with an abrupt dietary change and immature organ function, with a consequent reduction in growth. Thus, piglets around the post-weaning period are highly susceptible to enteric bacterial infections caused by opportunistic pathogens. The use of antibiotics and other medications to circumvent this critical period has been common in intensive systems; however, it has contributed to the development of antibioticresistant strains. Indeed, the last report from the European Food Safety Authority (EFSA) for the situation in 2015 documented an increase in multi-drug resistant (MDR) strains of Escherichia coli and Salmonella Typhimurium [1]. There is therefore an urgent need to search for alternatives that will diminish diarrhea outbreaks and help to reduce the use of therapeutic and prophylactic antibiotics.

Feeding strategies are one of the most commonly-used management factors for the improvement of gut health and function in newly weaned pigs. A wide range of bioactive ingredients have been proposed as tools to control enteric pathogens, to help reduce the incidence and severity of digestive problems associated with weaning [2]. Among them, medium-chain fatty acids (MCFA), considered fatty acids with a chain length of 6- to 12- carbon atoms, have been proposed as a potential alternative to antibiotics based on their long-known antibacterial activity [3]. In contrast to antimicrobial agents, MCFA have not shown evidence of acquiring resistance $[4,5]$. Besides this, MCFA are an immediate source of energy due to their rapid passive absorption and digestion, which is of particular interest for the nutrition of young animals [6, 7]. They occur naturally as medium-chain triglycerides (MCT) in milk fat, as well as in other vegetable sources, such as coconut or palm oils and Cuphea seed oil $[8,9]$. The most abundant MCFA in coconut is lauric acid (C12), representing up to $45 \%$ of the coconut fat content, followed by capric (C10) and caprylic (C8) acids [10]. C12 acid has been proven to have the greatest antimicrobial function among all MCFA $[4,11]$.

Several published works can be found substituting fat sources with purified MCFA or alternative natural sources rich in MCFA, leading to improvements in the performance of piglets around weaning [12, 13]. Studies with healthy pigs [14-16] have demonstrated positive effects on growth performance, digestibility, and intestinal microbiota. The antibacterial effect has also been widely demonstrated in vitro [3, 17], particularly against Salmonella or enterotoxigenic E. coli (ETEC), among other pathogens $[18,19]$. However, to our knowledge, most of the in vivo studies testing the effect of MCFA against pathogens were performed in rodents $[5,20]$ and chickens [21]. Only two studies have tested the potential of
MCFA in challenged pigs; one tested the control of Salmonella in fatteners under commercial conditions [22] and the other assessed the efficacy against an LPS challenge in an experimental trial with weanlings [23]. Within this context, the objective of this work was to evaluate the potential of a combination of sodium salts of medium-chain fatty acids distilled from coconut oil to enhance the gut health of weaned piglets in the face of diarrheic enteric diseases caused by Salmonella or ETEC F4 in controlled clinical assays.

\section{Methods}

Two different experiments were performed to evaluate the effect of the coconut distillates against an oral challenge with Salmonella Typhimurium (Trial 1) or ETEC F4 (Trial 2). Both trials were performed at the Servei de Granges i Camps Experimentals of the Universitat Autònoma de Barcelona (UAB). The treatment, management, housing, husbandry and slaughtering conditions conformed to European Union Guidelines (Directive 2010/63/EU).

\section{Animals, housing, and experimental design}

The two trials were conducted following Biosafety Level 2 requirements with appropriate training of the involved personnel. For the first trial, 56 male piglets from high sanitary status farms were used. The (Landrace $\times$ Large White) $\times$ Piétrain piglets originated from mothers with negative Salmonella serology results; they were weaned at $28 \mathrm{~d}$ of age and had an average body weight (BW) of $8.1 \pm 1.16 \mathrm{~kg}$. For the second trial, 72 male piglets (Landrace $\times$ Large White) $\times$ Piétrain that originated from mothers that were not vaccinated against $E$. coli were used; they were weaned at $21 \mathrm{~d}$ of age and had an average BW of $5.6 \pm 0.95 \mathrm{~kg}$.

The piglets were transported to the UAB facilities and for each trial, 48 animals were placed in 16 pens (three animals per pen). In each pen, the animals were distributed according to weight (a low-, an intermediate-, and a high-weighted animal) to obtain a final homogenous weight among pens. The experimental treatments were evenly distributed among the pens. The experimental treatments included a control treatment (CTR) consisting of a plain diet without additives and the same diet including a commercial blend of salts of MCFA distilled from coconut oil (Dicosan) at $3 \mathrm{~kg} / \mathrm{t}$ (DIC). The rest of the animals were kept in a separate room and used as controls for the challenges (placebo groups, PLB). For the first trial, eight piglets were distributed among four pens (two animals per pen), and for the second trial 24 piglets were distributed among eight pens (three animals per pen). Both placebo groups received the same plain diet given to the CTR groups and were euthanized at $d$ 4 post-inoculation (PI). 
Each pen $\left(3 \mathrm{~m}^{2}\right)$ had a feeder and a water nipple to provide feed and water for ad libitum consumption. The weaning rooms were equipped with automatic heating and forced ventilation. The experiments were conducted during the autumn-winter seasons (September-October and February-March for Trial 1 and 2, respectively) with a mean room temperature of $30.8 \pm 5.28{ }^{\circ} \mathrm{C}$. Both trials were maintained under a $13 \mathrm{~h}$ light $/ 11 \mathrm{~h}$ dark lighting regimen.

\section{Experimental products and diets}

The evaluated feed-additive is commercially available (Dicosan) and was supplied by Norel S.A. (Madrid, Spain). It consisted of a mixture of sodium salts of fatty acid obtained from the distillates of coconut oil $(67 \%$ crude fat and a fatty acid profile with $48.4 \%$ lauric acid, $18.6 \%$ myristic acid, 9.9\% palmitic acid, $6.8 \%$ oleic acid, 6.2\% caprylic acid, 5.8\% capric acid, $3.6 \%$ stearic acid and $1.3 \%$ linoleic acid).

The basal diet (Table 1) was formulated to satisfy the nutrient requirement standards for pigs [24]. For each trial, the diet was manufactured in the same batch and the additive was mixed with the corresponding amount of feed to obtain the DIC diet. Dicosan was included according to the manufacturer's recommended dosage (3 $\mathrm{kg} / \mathrm{t}$ ). The intended dose of the additive was not analytically confirmed in the diet, however, it was expected to provide $1.11 \mathrm{~kg} / \mathrm{t}$ of lauric acid.

\section{Bacterial strains}

For the first trial, the Salmonella strain used for the oral challenge was a monophasic variant of Salmonella Typhimurium (4,5,12:i:-) with a ACSSuT-Ge resistance profile and phage type U302; it was isolated from a salmonellosis outbreak in fattening pigs in Spain (mainly enteric with sporadic septicemia) and provided by the Infectious Diseases Laboratory of UAB (ref. 301/99). The oral inoculum was prepared by overnight incubation at $37^{\circ} \mathrm{C}$ and $250 \mathrm{r} / \mathrm{min}$ in buffered peptone water (BPW; Oxoid, Hampshire, UK) and diluted (1:20) with sterile phosphate buffered saline (PBS; Sigma-Aldrich, Madrid, Spain). The final inoculum concentration was $5.8 \times 10^{7} \mathrm{CFU} / \mathrm{mL}$. To confirm the doses, serial dilutions of the inoculum were cultured in tryptic soy agar (TSA; BD Difco, Heidelberg, Germany) by overnight incubation at $37^{\circ} \mathrm{C}$.

For the second trial, the enterotoxigenic Escherichia coli (ETEC) F4 strain used (positive for virulence factors F4ab, F4ac, LT, STb, and EAST1 and negative for F6, F18, F41, STa, VT1, VT2, and EAE) was isolated from 14-wk-old pigs and provided by the Diseases Laboratory of UAB (ref. 30/14-3). The oral inoculum was prepared by overnight incubation at $37^{\circ} \mathrm{C}$ and $250 \mathrm{r} / \mathrm{min}$ in brain heart infusion (BHI; Oxoid). The final inoculum was 2.5 $\times 10^{8} \mathrm{CFU} / \mathrm{mL}$. To confirm the doses, serial dilutions of
Table 1 Ingredient composition and chemical analysis of the basal diet on an as-fed basis

\begin{tabular}{|c|c|c|}
\hline \multicolumn{3}{|l|}{ Ingredients, g/kg } \\
\hline Maize & 205 & \\
\hline Wheat & 180 & \\
\hline Barley 2 row & 170 & \\
\hline Extruded soybean & 150 & \\
\hline Sweet whey-powder (cattle) & 112 & \\
\hline Fishmeal LT & 60.0 & \\
\hline Soybean meal 47 & 70.0 & \\
\hline Whey powder $50 \%$ fat & 25.0 & \\
\hline Mono-calcium phosphate & 6.5 & \\
\hline Calcium carbonate $\left(\mathrm{CaCO}_{3}\right)$ & 3.8 & \\
\hline L-Lysine $\mathrm{HCl}$ & 4.5 & \\
\hline Vitamin-Mineral premix ${ }^{a}$ & 4.0 & \\
\hline DL-Methionine 99 & 2.6 & \\
\hline Sodium chloride (marine salt) & 2.4 & \\
\hline L-Threonine & 2.3 & \\
\hline L-Valine & 1.5 & \\
\hline L-Tryptophan & 0.7 & \\
\hline \multicolumn{3}{|l|}{ Calculated nutrients, g/kg } \\
\hline Metabolizable energy, kcal/kg & 3381 & \\
\hline Calcium & 6.5 & \\
\hline Phosphorus & 6.6 & \\
\hline Sodium & 2.3 & \\
\hline Chloride & 5.7 & \\
\hline Potassium & 9.1 & \\
\hline Magnesium & 1.4 & \\
\hline Analyzed nutrients, g/kg & Salmonella trial & ETEC F4 trial \\
\hline Dry matter & 902 & 915 \\
\hline Ash & 54.2 & 48.2 \\
\hline Crude fat & 59.4 & 66.5 \\
\hline Crude protein & 198 & 195 \\
\hline Neutral detergent fiber & 84.3 & 81.7 \\
\hline Acid detergent fiber & 31.1 & 31.5 \\
\hline
\end{tabular}

a Provided per kilogram of complete diet: 10,200 IU vitamin A, 2,100 IU vitamin $D_{3}, 39.9 \mathrm{mg}$ vitamin $E, 3 \mathrm{mg}$ vitamin $\mathrm{K}_{3}, 2 \mathrm{mg}$ vitamin $B_{1}, 2.3 \mathrm{mg}$ vitamin $B_{2}, 3$ $\mathrm{mg}$ vitamin $B_{6}, 0.025 \mathrm{mg}$ vitamin $B_{12}, 20 \mathrm{mg}$ calcium pantothenate, $60 \mathrm{mg}$ nicotinic acid, $0.1 \mathrm{mg}$ biotin, $0.5 \mathrm{mg}$ folic acid, $150 \mathrm{mg} \mathrm{Fe}, 156 \mathrm{mg} \mathrm{Cu}, 0.5 \mathrm{mg}$ Co, $120 \mathrm{mg} \mathrm{Zn}, 49.8 \mathrm{mg} \mathrm{Mn}, 2 \mathrm{mg} \mathrm{l}$, and $0.3 \mathrm{mg} \mathrm{Se}$

the inoculum were cultured in Luria agar (LA; Laboratorios Conda, Torrejón de Ardoz, Spain) by overnight incubation at $37^{\circ} \mathrm{C}$.

In both trials, the placebo animals received the same amount of confirmed sterile broth inocula.

\section{Experimental procedure}

The animals received the experimental diets ad libitum over $14 \mathrm{~d}$ in the Salmonella trial and $15 \mathrm{~d}$ in the ETEC 
F4 trial. After 6 and $7 \mathrm{~d}$ of adaptation in the first and second trials, respectively, the animals were orally challenged with the pathogen or the sterile broth. One pig per pen was euthanized on $\mathrm{d} 4$ and 8 PI. The PLB animals were maintained until d 4 PI and thereafter euthanized following the same procedures performed on the challenged groups.

Fecal samples for microbiological analysis were aseptically collected from the heaviest piglet from each pen $(n=16)$ at arrival and after the adaptation period (d 0 PI), after spontaneous defecation or by rectal stimulation. After the adaptation period, the pathogenic bacteria inocula were administered by oral gavage to all animals as a single dose of Salmonella Typhimurium $\left(1.2 \times 10^{8}\right.$ CFU) or ETEC F4 $\left(1.48 \times 10^{9} \mathrm{CFU}\right)$ on $\mathrm{d} 7$ and 8 , respectively. In order to ensure that the stomach was full at the time of inoculation and to facilitate bacterial colonization, feed was withdrawn at 21:00 the previous day and provided once again $30 \mathrm{~min}$ before inoculation the following morning.

Individual BW and pen feed consumption were registered during the adaptation period. Body weight was further recorded on $\mathrm{d} 0,4$, and 8 PI in both trials, whereas feed consumption was recorded on d $0,2,4$, and 8 PI for the Salmonella trial and d 0, 1, 2, 3, 4, 5, 7, and 8 PI for the ETEC F4 trial. The average daily gain (ADG) and average daily feed intake (ADFI) were calculated per pen, which was considered the experimental unit.

After the oral challenge, animals were checked daily for clinical signs to evaluate their status (i.e. dehydration, apathy, fecal score), always by the same individual. Mortality was also registered. No antibiotic treatment was administered to any of the animals in any of the experiments. The fecal score was assessed using a scale: $1=$ solid and cloddy, 2 = soft with shape, 3 = very soft or viscous liquid, and $4=$ watery or with blood. A fecal score was registered individually on $\mathrm{d} 0,1,2,3$, and 7 PI in the Salmonella trial and on d 0, 1, 2, 3, 5, and 7 PI in the ETEC F4 trial. Rectal temperature was assessed using a digital thermometer (Accu-Vet, Import Vet S.A., Centelles, Spain) on d 0 and 2 PI. Within the Salmonella trial, additional fecal samples for microbiological analysis were collected from the same animals on $\mathrm{d} 1,3$, and 7 PI.

On $\mathrm{d} 4$ and 8 PI, one pig per pen was euthanized sequentially during the morning (between 08:00 and 14: 00) for sampling. On d 4 PI, the animal from each pen with the mid-weight at the beginning of the experiment was selected, and on $\mathrm{d} 8 \mathrm{PI}$, the animal with the highest weight was selected. A $10-\mathrm{mL}$ blood sample was obtained by venipuncture of the cranial vena cava using 10-mL tubes without anticoagulant (Aquisel, Madrid, Spain). Immediately, the animals received an intravenous injection of sodium pentobarbital $(200 \mathrm{mg} / \mathrm{kg} \mathrm{BW}$;
Euthasol, Esteve, Barcelona, Spain). Once dead, the animals were bled, the abdomen was immediately opened, and the intestinal tract was excised.

The digesta content from the ileum $(5 \mathrm{~cm}$ from the ileal-cecal junction) and proximal colon $(5 \mathrm{~cm}$ from the ceco-colic junction) was collected and homogenized, and the $\mathrm{pH}$ was immediately determined using a $\mathrm{pH}$-meter calibrated on each day of use (Crison 52-32 electrode, Net Interlab, Madrid, Spain). Different aliquots were collected for different determinations. Samples of approximately $5 \mathrm{~g}$ were kept immediately on dry ice until being stored at $-20^{\circ} \mathrm{C}$ for the further analysis of short-chain fatty acids (SCFA) and lactic acid, and similar aliquots were stored at $-80^{\circ} \mathrm{C}$ for the high-throughput sequencing (HTS) of colonic microbiota. Another set of samples were preserved in a $\mathrm{H}_{2} \mathrm{SO}_{4}$ solution $(3 \mathrm{~mL}$ of digesta plus $3 \mathrm{~mL}$ of $\left.0.2 \mathrm{~mol} / \mathrm{L} \mathrm{H}_{2} \mathrm{SO}_{4}\right)$ and stored at $-20^{\circ} \mathrm{C}$ until ammonia $\left(\mathrm{NH}_{3}\right)$ determination.

In the ETEC F4 trial, additional aliquots (approximately $2 \mathrm{~g}$ ) from the ileum and colon digesta were also kept on ice for microbiological analysis and were processed in less than $4 \mathrm{~h}$; other similar aliquots were stored at $-80^{\circ} \mathrm{C}$ for $E$. coli $\mathrm{F} 4$ quantification by real-time quantitative PCR (qPCR) and for the HTS of colonic microbiota. In parallel, to analyze the bacteria attached to the ileal mucus and epithelium, $15-\mathrm{cm}$ long sections of the ileum were excised, washed thoroughly three times with sterile PBS, opened longitudinally, and scraped with a microscope glass slide to obtain mucosa samples. One aliquot was kept on ice for microbial analysis. In the case of the Salmonella trial, additional cecum digesta samples were collected, kept on ice, and processed in less than $4 \mathrm{~h}$ for Salmonella counts.

For the histological study, 3-cm long sections from the distal ileum were removed, opened longitudinally, washed thoroughly with sterile PBS, and fixed by immersion in a formaldehyde solution 3.7-4\% (PanReac, Castellar del Vallès, Spain).

Blood samples were centrifuged $(1500 \times g$ for $15 \mathrm{~min})$ and the obtained serum was divided into different aliquots and stored at $-20^{\circ} \mathrm{C}$.

\section{Analytical procedures}

Chemical analyses of the diets including the content of dry matter (DM), ash, crude protein, and diethyl ether extract were performed according to the Association of Official Agricultural Chemists standard procedures [25]. Neutral detergent fiber and acid detergent fiber were determined according to the method of Van Soest et al. [26].

For microbial counts of Salmonella spp. (Trial 1), the cecum content and feces were suspended in buffered peptone water (BPW; 1:10). The quantitative determination consisted of 10-fold serial dilutions in PBS seeded 
in Xylose-Lactose-Tergitol-4 agar (XLT4; Merck, Madrid, Spain) and a count of $\mathrm{H}_{2} \mathrm{~S}$ positive colonies and morphology compatible with Salmonella spp. after $24 \mathrm{~h}$ incubation at $37{ }^{\circ} \mathrm{C}$. With this scheme, animals were given a count level as follows: negative, for animals with no Salmonella growth at $10^{2}$ dilution $\left(<10^{3} \mathrm{CFU} / \mathrm{g}\right.$ fresh matter [FM]); low, for animals with counts of $10^{3}$ to $10^{4} \mathrm{CFU} / \mathrm{g} \mathrm{FM}$; medium, for animals with counts of $10^{5}$ to $10^{6} \mathrm{CFU} / \mathrm{g} \mathrm{FM}$; and high, for animals with counts of $10^{7}$ to $10^{8} \mathrm{CFU} / \mathrm{g}$ FM.

For microbial counts of enterobacteria and total coliforms (Trial 2), the ileum and colon contents and feces were suspended in PBS (1:10), serially diluted in Lactated Ringer's Solution (Sigma-Aldrich), and seeded in MacConkey agar and Chromogenic agar (Oxoid), respectively. The counts were read after $24 \mathrm{~h}$ of incubation at $37^{\circ} \mathrm{C}$.

In addition, for microbial molecular analysis, DNA was extracted from samples (approximately $250 \mathrm{mg}$ ) and purified using the commercial QIAamp DNA Stool Mini Kit (Qiagen, West Sussex, UK). Subsequently, its concentration and purity were checked using a NanoDrop 1000 Spectrophotometer (Thermo Fisher, Wilmington, $\mathrm{DE})$. The protocol was followed, applying all recommended optimization steps, in order to improve bacterial cell rupture and purity. The DNA was finally eluted in $200 \mathrm{~mL}$ of Qiagen buffer $\mathrm{AE}$ and stored at $-80^{\circ} \mathrm{C}$ until use.

E. coli $\mathrm{F} 4$ was quantified in colonic digesta and ileal scrapings by qPCR using SYBR green dye. qPCR targeting the gene coding the $\mathrm{F} 4$ fimbria of ETEC F4 was performed by modifying the procedure described by Gustavo Hermes et al. [27]; the changes consisted of using SYBR Green PCR Master Mix PCR (Applied Biosystems, Carlsbad, CA) and reducing the total volume of the reaction to $20 \mu \mathrm{L}$, which included $10 \mu \mathrm{L}$ of $2 \times$ SYBR Green PCR Master Mix PCR buffer, $0.88 \mu \mathrm{L}$ of each primer $(12.5 \mu \mathrm{mol} / \mathrm{L})$, and $5 \mu \mathrm{L}$ of the DNA sample.

In the case of the HTS of the colonic microbiota in both trials, the V3-V4 region of 16S rRNA was targeted using $\mathrm{MiSeq}^{\circ}$ Reagent Kit v2 (500 cycles; MiSeq from Illumina, San Diego, CA). The primers used in the construction of the libraries with amplicons of putative 460 bp were as follows:

\section{F-5' -TCGTCGGCAGCGTCAGATGTGTATAAGA GACAGCCTACGGGNGGCWGCAG$$
\text { R-5' -GTCTCGTGGGCTCGGAGATGTGTATAAG }
$$$$
\text { AGACAGGACTACHVGGGTATCTAATCC }
$$

The sequence reads of the 16S rRNA gene generated from the MiSeq Illumina system were processed using the QIIME v.1.9.1 pipeline [28] with default settings. The quality filter of the already demultiplexed sequences was performed at a maximum unacceptable Phred quality score of Q20. The resulting reads were clustered to operational taxonomic units (OTUs) using uclust with 97\% sequence similarity and a subsampling pick open reference method [29] at 10\%. Representative sequences were assigned to taxonomy against the bacterial $16 \mathrm{~S}$ GreenGenes v.13.8 reference database [30] at a 90\% confidence threshold, and sequence alignment and phylogenetic tree building were performed using uclust and FastTree, respectively. Thereafter, chimeric sequences were removed with ChimeraSlayer [31] using the default settings and further quality filtering consisted of removing singletons and OTUs with a relative abundance below $0.005 \%$ across all samples, as recommended by Bokulich et al. [32].

The ammonia $\left(\mathrm{NH}_{3}\right)$ concentration was determined with the aid of a gas-sensitive electrode (Hach Co., Loveland, $\mathrm{CO}$ ), combined with a digital voltmeter (Crison GLP 22, Crison Instruments S.A., Barcelona, Spain), modified from Barba-Vidal et al. [33]. Three grams of digesta preserved in $\mathrm{H}_{2} \mathrm{SO}_{4}$ (1:2) was centrifuged at 1372 $\times g$ for 10 min. A supernatant was obtained and neutralized with $1 \mathrm{~mL}$ of $10 \mathrm{~mol} / \mathrm{L} \mathrm{NaOH}$ to reach a $\mathrm{pH}$ of 11 , while stirring and measuring the ammonia released as different voltages in $\mathrm{mV}$.

The SCFA and lactic acid concentrations were determined based on the method described by Richardson et al. [34] and modified by Jensen et al. [35] using gas chromatography after submitting the samples to an acid-base treatment, followed by a diethyl ether extraction and derivatization with $\mathrm{N}$-(tertbutyldimethylsilyl)- $N$-methyl-trifluoroacetamide (MBTSTFA) plus 1\% tert-butyldimethylchlorosilane (TBDMCS) agent (Sigma-Aldrich).

Tissue samples for morphological measures were dehydrated and embedded in paraffin wax, sectioned to $4-\mu \mathrm{m}$ thick slices and stained with hematoxylin and eosin. The morphological measurements (villus height and crypt depth, counts of intra-epithelial lymphocytes and goblet cells in the villus, and counts of mitoses in the crypt) of 10 different villus-crypt pairs were performed using a light microscope (Leica DM5000B, Jenoptik, Barcelona, Spain) fitted to CapturePro software (ProgRes ${ }^{\oplus}$, Jenoptik, Barcelona, Spain), using the technique described by Nofrarías et al. [36].

Serum concentrations of tumor-necrosis factor- $\alpha$ (TNF- $\alpha$ ) were determined using Quantikine Porcine TNF- $\alpha$ kits (R\&D Systems, Minneapolis, MN); the pigmajor acute-phase protein (Pig-MAP) concentration was determined using a sandwich-type ELISA (Pig MAP Kit ELISA, Pig CHAMP Pro Europe S.A., Segovia, Spain). In the Salmonella trial, serological antibodies of Salmonella were tested using ELISA Herdchek Swine Salmonella (IDEXX, Hoofdorp, Netherlands). 


\section{Statistical analysis}

The effect of the experimental treatments on the performance and slaughter measurements was determined using the free software R v.3.4.3, using the stats package [37] $\mathrm{lm}$ function for a one-way ANOVA, with diet as a fixed effect. For the microbial analysis, in Trial 2, enterobacteria and coliform counts were $\log _{10}$-transformed and submitted to the same one-way ANOVA analysis. In the case of Trial 1, Salmonella spp. count levels were analyzed with the stats package likelihood.test function for frequency analysis; the number of positive animals for Salmonella spp. followed the stats package glm function under a binomial distribution. The Pig-MAP concentration levels were also analyzed with the same frequency analysis, considering the normal range $(0.3-1 \mathrm{mg} / \mathrm{mL})$, borderline $(1-2 \mathrm{mg} / \mathrm{mL}$ ), and high levels $(>2 \mathrm{mg} / \mathrm{mL}$ ) [38], and the number of animals with detectable copies of the pathogen F4 gene or quantifiable levels of fermentation products (SCFA and lactic acid) were analyzed under a binomial distribution.

The average daily feed intake, rectal temperature, and daily fecal consistency were assessed using the lme4 package [39] lmer function for an adjusted linear mixed model, with a treatment-by-time interaction term.

For all analyzed data, the pen was the experimental unit. The alpha level for the determination of significance for all the analyses was 0.05 . Statistical trends were also considered for $0.05<P<0.10$, unless otherwise indicated. Data are presented as means and residual standard error (RSE).

Biostatistics of quality-filtered sequences were performed using the open source software R v.3.4.3. Firstly, an OTU table was imported into $\mathrm{R}$ with the phyloseq package [40]; only OTUs that were shared among experimental groups were included and unique OTUs were excluded. Diversity and ordination (non-multidimensional scaling, NMDS) were analyzed at the OTU level using the vegan package [41]. The richness and alpha diversity were calculated with raw counts based on the Chao1 estimator [42] to estimate the number of taxa in the community, and the Shannon index [43], which considers the richness as well as the evenness. For beta diversity, the Whittaker distance matrix was calculated based on the relative abundances using the betadisper function. To compare any differential effects from treatments, an ANOVA was performed for richness and diversity. For ordination analysis, a dissimilarity matrix based on the Bray-Curtis distances was also calculated with relative abundances and two different fitting model analyses were applied. The function envfit, which fits centroids of class variable levels defined as a factor onto an ordination, was used, and the anosim function was used for the analysis of similarities (ANOSIM). Finally, a differential abundance analysis was performed with the
OTU and taxa relative abundances under a zero-altered negative binomial or negative binomial model with pscl [44] and mass [45] packages, respectively, and corrected for the false-discovery rate (FDR).

\section{Results}

In both studies, the animals showed a good health status on arrival, with most of the animals adapting to the facilities and feed positively. Both challenges promoted a clinical course of diarrhea in most of the animals, who were recovering spontaneously at the end of the study. Some casualties were registered in both trials. After the Salmonella challenge, one animal from the DIC group was found dead on d 4 PI and two animals from the DIC and CTR groups, respectively, were found dead on d 6 PI. Within the ETEC F4 challenge, one animal from the CTR group was found dead on $\mathrm{d} 1 \mathrm{PI}$ and a second animal from the DIC group had to be euthanized following the clinical flowchart on d 3 PI. There were no statistical differences in the number of causalities between the treatments $(P>0.05)$ in any of the trials.

\section{Animal performance}

The effects of the experimental treatments on animal performance are shown in Table 2. There were no significant effects on the final BW, ADFI, or ADG with the administration of DIC in any of the trials, except for a lower ADG $(P=0.032)$ for the DIC group than the CTR

Table 2 Effect of the experimental diets on animal performance in the Salmonella and ETEC F4 trials

\begin{tabular}{|c|c|c|c|c|c|c|c|c|}
\hline \multirow[t]{2}{*}{ Items } & \multicolumn{4}{|c|}{ Salmonella Trial } & \multicolumn{4}{|c|}{ ETEC F4 Trial } \\
\hline & CTR & DIC & RSE & $P$ & CTR & $\mathrm{DIC}$ & RSE & $P$ \\
\hline \multicolumn{9}{|l|}{ BW, kg } \\
\hline Initial & 8.1 & 8.1 & 0.14 & 0.900 & 5.6 & 5.6 & 0.10 & 0.239 \\
\hline Final & 10.8 & 9.9 & 0.12 & 0.164 & 7.8 & 7.6 & 0.69 & 0.553 \\
\hline \multicolumn{9}{|l|}{$A D F I, g / d$} \\
\hline Prel $^{a}$ & 233 & 226 & 28.1 & 0.598 & 178 & 162 & 38.4 & 0.431 \\
\hline $4 \mathrm{PI}^{\mathrm{b}}$ & 218 & 193 & 46.7 & 0.302 & 219 & 211 & 45.8 & 0.729 \\
\hline $8 \mathrm{Pl}^{\mathrm{C}}$ & 428 & 443 & 79.5 & 0.713 & 282 & 276 & 82.0 & 0.894 \\
\hline Overall $^{d}$ & 285 & 278 & 41.5 & 0.766 & 221 & 211 & 46.6 & 0.664 \\
\hline \multicolumn{9}{|l|}{$A D G, g / d$} \\
\hline Prel $^{a}$ & 122 & 109 & 60.7 & 0.675 & 77 & 78 & 41.6 & 0.986 \\
\hline $4 \mathrm{Pl}^{\mathrm{b}}$ & -4 & -38 & 108.7 & 0.541 & 129 & 117 & 90.5 & 0.796 \\
\hline $8 \mathrm{Pl}^{\mathrm{c}}$ & 326 & 316 & 162.6 & 0.903 & 260 & 164 & 80.6 & 0.032 \\
\hline Overall ${ }^{d}$ & 144 & 126 & 70.9 & 0.616 & 140 & 111 & 43.3 & 0.207 \\
\hline
\end{tabular}

$A D F I$ Average daily feed intake, $A D G$ Average daily gain, $B W$ Body weight, $P I$ Post-inoculation day, RSE Residual standard error

a Pre-inoculation period from 0-7 $\mathrm{d}$ or 0-6 $\mathrm{d}$ before inoculation in the Salmonella and ETEC F4 trials, respectively

${ }^{\text {b} P e r i o d ~ f r o m ~ 0-4 ~ d ~ p o s t-i n o c u l a t i o n ~}$

'Period from 4-8 d post-inoculation

dPeriod from experimental day 1-14 or 1-15 in the Salmonella and ETEC F4 trials, respectively 
group during the second PI period (4-8 d PI) in the ETEC F4 trial. Regarding the performance response in the PLB groups, in the Salmonella trial the ADG was 33 $\pm 76.0 \mathrm{~g} / \mathrm{d}$ during the adaptation week, and $306 \pm 92.3$ $\mathrm{g} / \mathrm{d}$ during the 4-PI period, whereas in the ETEC F4, these values were $75 \pm 42.9 \mathrm{~g} / \mathrm{d}$ and $174 \pm 63.8 \mathrm{~g} / \mathrm{d}$, respectively. The ADFIs observed in the first trial for the PLB group were $184 \pm 26.4 \mathrm{~g} / \mathrm{d}$ and $379 \pm 71.2 \mathrm{~g} / \mathrm{d}$ during the pre- and post-inoculation days, respectively, and those in the second trial for the PLB groups were $187 \pm$ $59.8 \mathrm{~g} / \mathrm{d}$ and $255 \pm 24.6 \mathrm{~g} / \mathrm{d}$, respectively.

\section{Clinical signs}

The evolution of the fecal consistency throughout the post-inoculation (PI) period is presented in Fig. 1. After the oral challenge, fecal consistencies were impaired in both trials. The inoculation of Salmonella led to an evident liquid diarrhea (time $P<0.001$ ), with scores reaching level 3 in most of the animals on d 2 PI. After the ETEC inoculation, diarrhea was observed (time $P=0.015$ ) in a limited number of animals (barely reaching scores of 1.8). There were no significant differences related to the experimental diets for any of the trials $(P>0.31)$.

The Salmonella challenge increased the rectal temperature $\left(40.6 \pm 0.27^{\circ} \mathrm{C}\right.$ on d 2 PI vs. $39.4 \pm 0.22{ }^{\circ} \mathrm{C}$ on d 0 PI; day $P<0.001)$. The ETEC F4 challenge did not affect this variable $\left(39.1 \pm 0.35{ }^{\circ} \mathrm{C}\right.$ on $\mathrm{d} 2$ PI vs. 39.0 $\pm 0.24{ }^{\circ} \mathrm{C}$ on $\mathrm{d} 0 \mathrm{PI}$; day $P=0.21$ ). In relation to the effect of diets, DIC had no significant influence on rectal temperature $(P>0.6)$.

\section{Inflammatory response}

After the Salmonella challenge, the CTR group presented higher concentrations of TNF- $\alpha(312 \pm 129.2 \mathrm{pg} /$ $\mathrm{mL}$ vs. $106 \pm 15.9 \mathrm{pg} / \mathrm{mL}$ in PLB) and Pig-MAP (3.08 \pm $2.812 \mathrm{mg} / \mathrm{mL}$ vs. $0.53 \pm 0.140 \mathrm{mg} / \mathrm{mL}$ in PLB) on $\mathrm{d} 4$ PI than the PLB groups. After the ETEC challenge, a higher response of both biomarkers was also observed in CTR groups than the PLB groups $(156 \pm 52.1 \mathrm{pg} / \mathrm{mL}$ in CTR vs. $123 \pm 17.4 \mathrm{pg} / \mathrm{mL}$ in PLB, and $1.56 \pm 1.545 \mathrm{mg} / \mathrm{mL}$ in CTR vs. $1.22 \pm 1.055 \mathrm{mg} / \mathrm{mL}$ in PLB, for TNF- $\alpha$ and Pig-MAP, respectively). As expected, from day 4 to $8 \mathrm{PI}$, the TNF- $\alpha(149 \pm 69.2 \mathrm{pg} / \mathrm{mL}$ and $113 \pm 20.3 \mathrm{pg} / \mathrm{mL}$ for Trial 1 and 2, respectively) and Pig-MAP concentrations $(0.96 \pm 0.469 \mathrm{mg} / \mathrm{mL}$ and $1.46 \pm 0.417 \mathrm{mg} / \mathrm{mL}$ for Trial 1 and 2, respectively) were decreased in the CTR groups. We were not able to detect statistical differences related to the experimental diets for any of the variables on any sampling day.

\section{Microbiological analysis}

In the Salmonella trial, none of the animals seeded Salmonella in their feces on arrival nor after the $6 \mathrm{~d}$ of adaptation. The serological analysis from day 4 PI confirmed that the animals had not been exposed to Salmonella prior to the inoculation. PLB group remained negative for Salmonella spp. until d 4 PI. Only one piglet per group (CTR and DIC) seroconverted on d 8 PI by applying a cut-off of an optical density percentage $(\mathrm{OD} \%) \geq 40$. Regarding the pathogen loads, all animals became positive, however, not all animals seeded countable numbers of the pathogen $\left(>10^{3} \mathrm{CFU} / \mathrm{g}\right.$ FM). Supplementation with DIC reduced the number of animals with countable numbers in their cecum content, particularly on d 8 PI (Table 3).

Figure 2 shows the different levels of Salmonella spp. excretion in the feces and cecal content for the experimental diets. Although the differences were not statistically significant, there was a trend for DIC to increase the Salmonella counts in feces shortly after inoculation (d 1 PI, $P=0.10$; and d 3 PI, $P=0.09$ ), but to clear the pathogen more efficiently from the cecum on day 4 PI than the CTR group $(P=0.07)$. At the end of the study

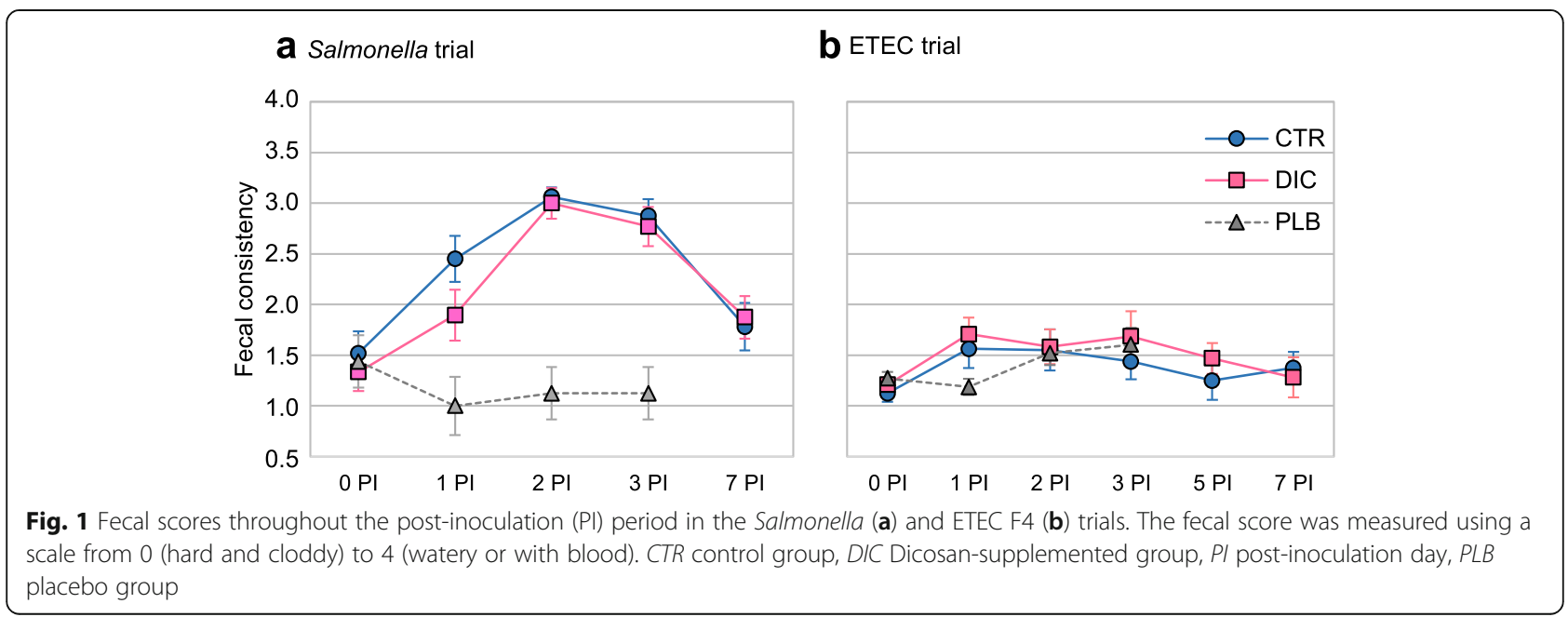


Table 3 Effect of the experimental diets on the numbers of Salmonella spp. ${ }^{\text {a }}$ in the Salmonella trial

\begin{tabular}{clll}
\hline Items & \multicolumn{2}{l}{ Salmonella Trial } & \\
\cline { 2 - 4 } & CTR & DIC & $P$ \\
\hline Feces & $7 / 8$ & $8 / 8$ & 0.228 \\
$1 \mathrm{PI}$ & $8 / 8$ & $6 / 8$ & 0.080 \\
$3 \mathrm{PI}$ & $3 / 8$ & $2 / 8$ & 0.589 \\
$7 \mathrm{PI}$ & & & \\
Cecum digesta & & $5 / 7$ & 0.065 \\
$4 \mathrm{PI}$ & $8 / 8$ & $3 / 8$ & 0.033 \\
$8 \mathrm{PI}$ & $7 / 8$ & & \\
\hline
\end{tabular}

$P /$ post-inoculation day

${ }^{a}$ Number of animals with countable numbers of Salmonella spp. $\left(<10^{3} \log _{10}\right.$ (FU/g FM)

(d $8 \mathrm{PI}$ ), there was also an increase in the number of animals with unquantifiable counts (very low) in the cecum with the DIC treatment (63\% vs. $12 \%$ for DIC and CTR, respectively; $P=0.26$ ).

Regarding the ETEC F4 trial, there were no significant differences related to the experimental trials in the enterobacteria nor coliform plate counts in the feces upon arrival or from after the week of adaptation $(9.77 \pm 0.282$ and 9.70 $\pm 0.360 \log _{10} \mathrm{CFU} / \mathrm{g}$ FM, respectively). Table 4 shows the microbiological analysis on $\mathrm{d} 4$ and 8 PI of the ileal and colonic digesta, and also of the ileal mucosa scrapings. On d 4 $\mathrm{PI}$, the counts of both bacterial groups were not different between the diets. However, on d $8 \mathrm{PI}$, animals receiving DIC consistently had reduced numbers of enterobacteria and coliforms in their ileum and colon content compared to those who received the CTR treatment. This effect was particularly apparent in the ileum, with decreases of more than one $\log _{10}$ unit (5.38 vs. $6.71 \log _{10} \mathrm{CFU} / \mathrm{g}$ FM, $P=$ 0.004; and 5.33 vs. $6.51 \log _{10}$ CFU/g FM, $P=0.05$ ) for enterobacteria and coliforms, respectively. The attached enterobacteria in the ileal mucosa also tended to be reduced with DIC on d 8 PI compared to the CTR diets $(P=$ 0.08).

The pathogen was not always present at quantifiable levels (limit of detection $3.83 \log _{10}$ F4 gene copies/g FM). A slight trend was found between the diets on $\mathrm{d} 4$ PI in terms of the prevalence of the pathogen $(P=0.10)$, with all the CTR animals (8/8 animals) but not all from the DIC treatment (6/8 animals) being positive for $E$. coli $\mathrm{F} 4$ in the colon digesta. On day $8 \mathrm{PI}$, the pathogen presence was reduced in both groups, with no significant differences between them $(P=0.30 ; 2 / 8$ vs. $4 / 8$ animals for CTR and DIC, respectively), and similar loads (5.11 and $5.24 \log _{10}$ F4 gene copies/g FM for the CTR and DIC groups, respectively). In the PLB group, the number of animals positive for $E$. coli $\mathrm{F} 4$ on day 4 PI was $5 / 8$ with mean count of $3.23 \log _{10}$ F4 gene copies/g FM, which is below the limit of detection.

\section{Microbiota 16S rRNA gene analysis}

With the objective of assessing changes promoted by the additives to the intestinal microbiota, we analyzed colonic digesta samples taken on $\mathrm{d} 8$ PI by highthroughput sequencing (HTS) of the V3-V4 regions of the $16 \mathrm{~S}$ rRNA gene.

The microbiota analysis was performed using a more conservative approach, by using the OTU core, including only those species shared between experimental treatments, within each experiment (836/843 OTUs in Trial 1 and 833/848 OTUs in Trial 2). Regarding the evenness of the reads, similar values were obtained when comparing treated groups to CTR ones $(P>0.34 ; 4.94 \pm 0.375$ and $4.82 \pm 0.243 \log _{10}$ no. reads/sample in Trial 1 and

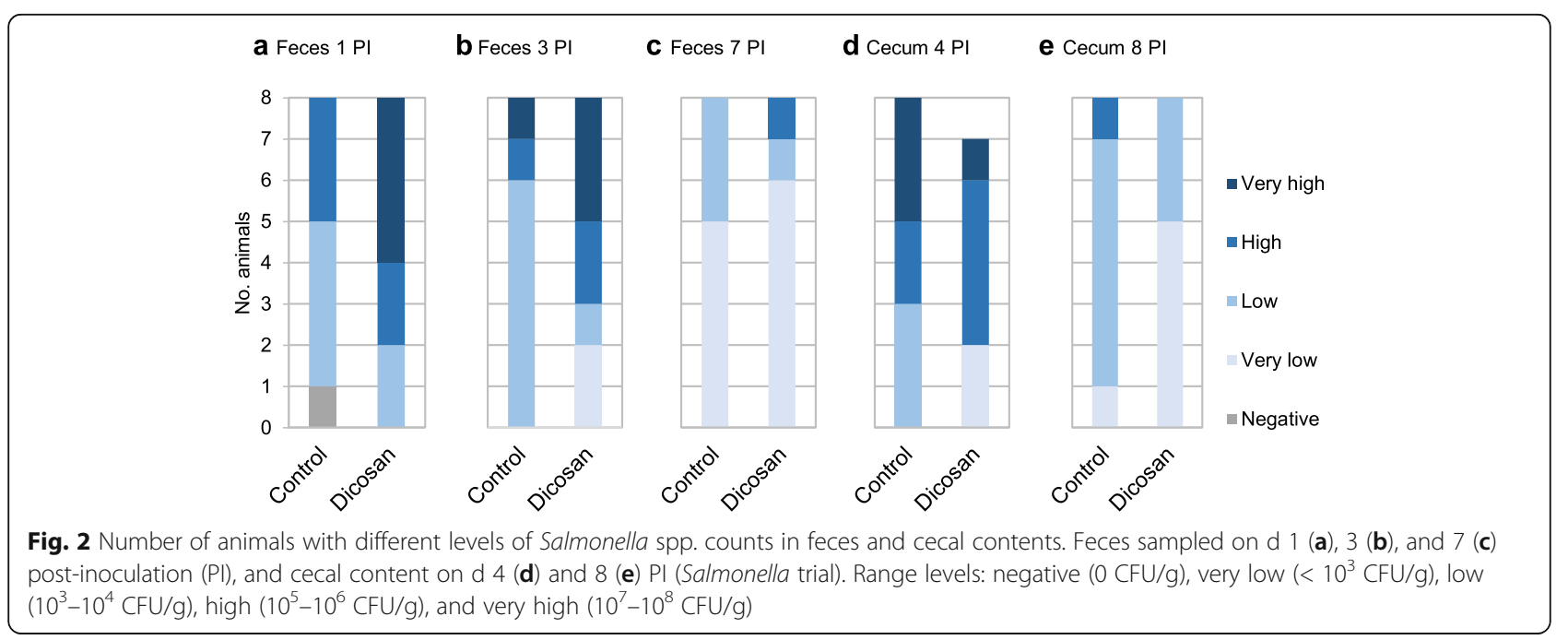


Table 4 Effect of the experimental diets on enterobacteria and coliform counts in the ETEC F4 trial

\begin{tabular}{|c|c|c|c|c|}
\hline \multirow[t]{2}{*}{ Items } & \multicolumn{4}{|c|}{ ETEC F4 trial } \\
\hline & $\overline{\mathrm{CTR}}$ & $\mathrm{DIC}$ & RSE & $P$ \\
\hline \multicolumn{5}{|c|}{ Ileum digesta } \\
\hline \multicolumn{5}{|c|}{ Enterobacteria, $\log _{10} \mathrm{CFU} / \mathrm{g} \mathrm{FM}$} \\
\hline $4 \mathrm{Pl}$ & 6.81 & 6.76 & 0.616 & 0.872 \\
\hline $8 \mathrm{Pl}$ & 6.71 & 5.38 & 0.783 & 0.004 \\
\hline \multicolumn{5}{|c|}{ Coliforms, $\log _{10}$ CFU/g FM } \\
\hline $4 \mathrm{PI}$ & 6.02 & 6.08 & 0.923 & 0.889 \\
\hline $8 \mathrm{Pl}$ & 6.51 & 5.33 & 0.829 & 0.013 \\
\hline \multicolumn{5}{|c|}{ Colon digesta } \\
\hline \multicolumn{5}{|c|}{ Enterobacteria, $\log _{10} \mathrm{CFU} / \mathrm{g} \mathrm{FM}$} \\
\hline $4 \mathrm{PI}$ & 10.7 & 9.9 & 1.16 & 0.213 \\
\hline $8 \mathrm{Pl}$ & 10.9 & 9.9 & 1.03 & 0.083 \\
\hline \multicolumn{5}{|c|}{ Coliforms, $\log _{10}$ CFU/g FM } \\
\hline $4 \mathrm{Pl}$ & 8.9 & 8.9 & 0.99 & 0.974 \\
\hline $8 \mathrm{Pl}$ & 10.8 & 9.8 & 0.98 & 0.052 \\
\hline \multicolumn{5}{|c|}{ Ileum mucosa } \\
\hline \multicolumn{5}{|c|}{ Enterobacteria, $\log _{10}$ CFU/g FM } \\
\hline $4 \mathrm{Pl}$ & 5.94 & 6.32 & 0.860 & 0.383 \\
\hline $8 \mathrm{Pl}$ & 6.17 & 5.16 & 0.786 & 0.082 \\
\hline \multicolumn{5}{|c|}{ Coliforms, $\log _{10}$ CFU/g FM } \\
\hline $4 \mathrm{Pl}$ & 5.53 & 5.47 & 1.117 & 0.921 \\
\hline $8 \mathrm{Pl}$ & 5.48 & 5.09 & 1.093 & 0.489 \\
\hline
\end{tabular}

CFU Colony-forming units, FM Fresh matter, PI Post-inoculation day, RSE Residual standard error

Trial 2, respectively). The Chao1 index did not differ between the groups $(P>0.74)$.

Regarding the microbial diversity or structure, DIC administration did not alter the alpha or beta diversity (Whittaker index) after Salmonella inoculation. After ETEC F4 inoculation, however, DIC administration did change the Bray-Curtis distances (microbial structure) as shown in Fig. 3 for the NMDS results (envfit $P=$ 0.035 and ANOSIM $P=0.177$ ).

Focusing on the aggregated taxa counts, Firmicutes and Bacteroidetes were the two major phyla ( $\geq 40 \%$ ), with Proteobacteria following thereafter $(7.3 \pm 4.25 \%$ in the Salmonella trial and $9.1 \pm 5.30 \%$ in the ETEC F4 trial). A few minor phyla (< $1 \%)$ : Elusimicrobia, Fibrobacteres, Lentisphaerae, and Verrumicrobia, were encountered in the Salmonella-challenged animals.

The majority of the families observed in both trials were, by order of abundance: Prevotellaceae $(27.9 \pm 10.68 \%$ and $29.0 \pm 7.52 \%$ in Trial 1 and 2, respectively), Veillonellaceae $(22.7 \pm 9.55 \%$ and $15.4 \pm 5.32 \%$ in Trial 1 and 2 , respectively), Rumminococcaceae (11.4 $\pm 3.42 \%$ and $11.4 \pm 2.63 \%$ in Trial 1 and 2, respectively) and Lachnospiraceae (8.29 \pm $3.555 \%$ and $9.25 \pm 3.307 \%$ in Trial 1 and 2, respectively);

\section{a Salmonella trial}

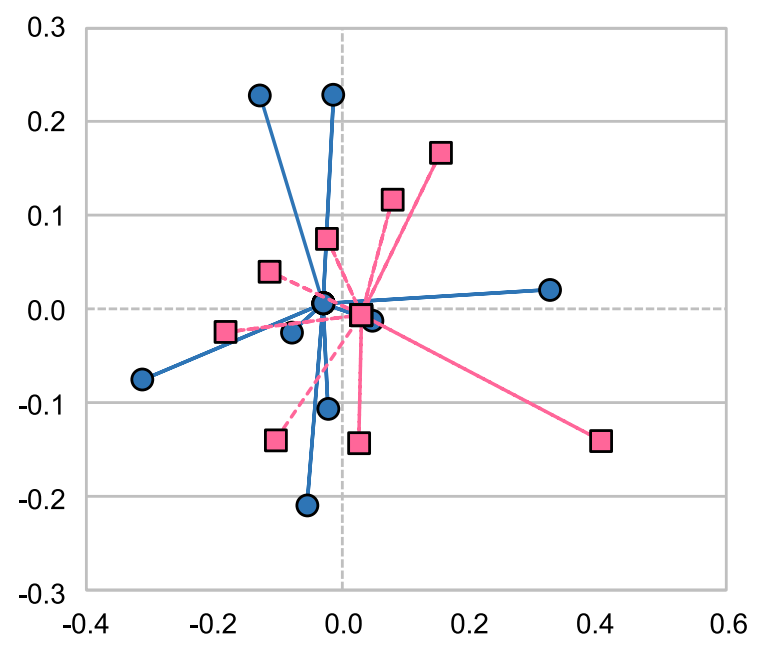

\section{b ETEC F4 trial}

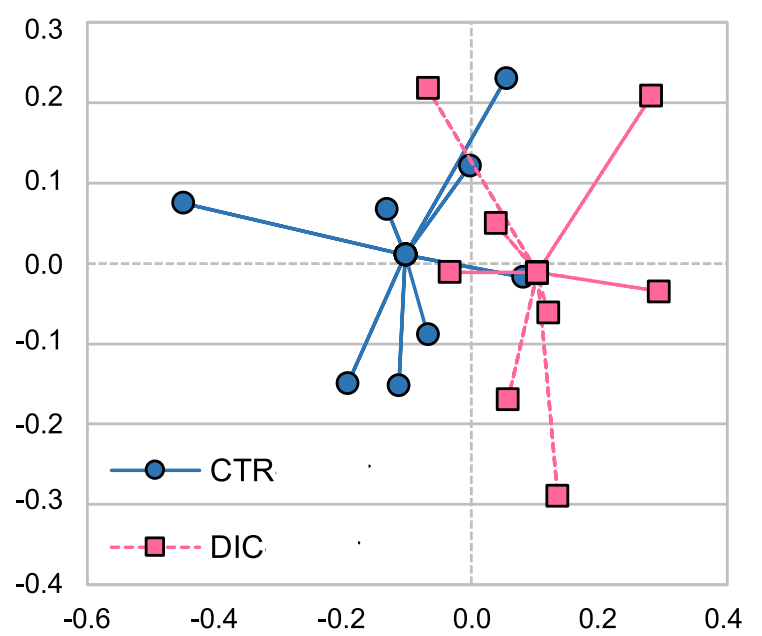

Fig. 3 Non-metric dimensional scaling (NMDS) plot of the dissimilarity matrix based on Bray-Curtis distance. Clustering by experimental diets for the Salmonella (a) and ETEC trial (b) from colon digesta samples collected on day 8 post-inoculation (PI). CTR control group, DIC Dicosan-supplemented group

41 and 42 different families were detected per trial, respectively, representing approximately $5 \%$ of the sum of the least abundant ones $(<1 \%, 31$ families per trial). Among the genera detected, Prevotella was the most prevalent $(28.0 \pm 10.7 \%$ and $29.0 \pm 7.52 \%$ in Trial 1 and 2 , respectively). A total of 55 genera were found in the Salmonella and 54 in the ETEC F4 trials, and 40 and 42 genera were underrepresented $(<1 \%)$ in Trial 1 and 2 , respectively, accounting for approximately $8 \%$ of the total abundance. Unknown taxa represented $7.2 \pm 2.87 \%$ and $6.7 \pm 2.05 \%$ of the families in the Salmonella and ETEC F4 trials, respectively, whereas they represented $24.8 \pm$ $6.63 \%$ and $27.2 \pm 4.72 \%$ of the genera, respectively. 
Regarding the influence of DIC, the Firmicutes:Bacteroidetes $(\mathrm{F} / \mathrm{B})$ ratio showed a trend of a numerical decrease $(P=0.132)$ in the Salmonella trial with DIC (1.14 vs. 1.47 in the CTR group). In the ETEC F4 trial, F/B ratio was unaffected (1.23 vs. 1.05 in the CTR group, $P=0.335$ ).

The effects of DIC on specific populations are also presented in Table 5, considering only the taxa found in at least half of the samples. At the phylum level, under the Salmonella challenge, only the minor phylum Fibrobacteres $(<1 \%)$ was increased in DIC-supplemented animals compared to the CTR $(P=0.02)$ animals. In parallel, the corresponding family and genus, Fibrobacteraceae and Fibrobacter, respectively, were enriched in the DIC animals compared to the CTR animals $(P<$ $0.05)$. Other changes in the Salmonella trial were also observed in minor families $(<1 \%)$, such as lower numbers of the candidate Barnesiellaceae and also in genera such as Dialister, Lachnobacterium and Butyrivibrio $(P<$ $0.10)$. Although not significant, there was a relevant numerical decrease in the abundance of the Enterobacteriaceae family in DIC animals compared to in the CTR animals $(P=0.16)$.
When considering the changes produced at the OTU level, i.e., species, only those found in at least half of the samples were considered. Table 6 presents the differences promoted by DIC $(P<0.05)$. As observed in the aggregated taxa, in the Salmonella trial, several OTUs assigned to Lachnospiraceae (new refs. OTU-2808 and 2343, and OTU-296082) were proportionally lower in DIC animals than CTR animals, including the Lachnobacterium genus (OTU-584463). In addition, a Spirochaetes-associated OTU was promoted in DIC animals (OTU-300859) and, in addition, several OTUs associated with Prevotella (within Bacteroidetes) were increased in DIC animals, possibly explaining the previously mentioned reduction in the F/B ratio. Nonetheless, other OTUs also corresponding to Bacteroidetes were in lower numbers, which highlights the high variability within a taxonomic group and the importance of considering the strain.

When focusing on populations under the ETEC F4 challenge (Table 5), few changes were observed in DICsupplemented animals; Dialister $(P=0.008)$ was significantly increased and Lachnospira tended to be reduced

Table $\mathbf{5}$ Ln changes in taxa promoted by DIC supplementation in the Salmonella and ETEC F4 trials

\begin{tabular}{|c|c|c|c|}
\hline Taxonomic rank & Taxon & Ln change $^{\mathrm{a}}$ (DIC vs. CTR) & Adjusted $P^{\mathrm{b}}$ \\
\hline \multicolumn{4}{|l|}{ Salmonella trial } \\
\hline Phylum & Fibrobacteres & 2.229 & 0.019 \\
\hline \multirow[t]{5}{*}{ Family } & cand. Barnesiellaceae & -4.499 & 0.003 \\
\hline & Fibrobacteraceae & 2.229 & 0.024 \\
\hline & Enterobacteriaceae & -1.746 & 0.157 \\
\hline & Spirochaetaceae & 1.326 & 0.192 \\
\hline & Alcaligenaceae & 0.876 & 0.192 \\
\hline \multirow[t]{4}{*}{ Genus } & Dialister & -0.690 & 0.000 \\
\hline & Fibrobacter & 2.225 & 0.033 \\
\hline & Lachnobacterium & -3.219 & 0.035 \\
\hline & Butyrivibrio & -1.251 & 0.095 \\
\hline \multicolumn{4}{|l|}{ ETEC F4 trial } \\
\hline \multirow[t]{4}{*}{ Family } & Veillonellaceae & 0.363 & 0.136 \\
\hline & Oxalobacteraceae & -0.804 & 0.151 \\
\hline & Deferribacteraceae & 1.915 & 0.151 \\
\hline & Turicibacteraceae & -1.384 & 0.176 \\
\hline \multirow[t]{7}{*}{ Genus } & Dialister & 5.981 & 0.008 \\
\hline & Lachnospira & -0.841 & 0.069 \\
\hline & Megasphaera & 1.137 & 0.149 \\
\hline & Coprococcus & -1.051 & 0.149 \\
\hline & Oxalobacter & -0.804 & 0.173 \\
\hline & Mucispirillum & 1.915 & 0.173 \\
\hline & Turicibacter & -1.384 & 0.183 \\
\hline
\end{tabular}

${ }^{a}$ Positive values and negative values indicate higher and lower abundance, respectively, in treated animals. Taxa are sorted by level of significance (from higher to lower). The presented differences are based only on taxa detected in at least half of the samples per diet

${ }^{\mathrm{b}}$ Adjusted $P$ value $<0.20$ 
Table 6 Differentially abundant OTUs ${ }^{a}$ between the DIC and CTR groups in the Salmonella and ETEC F4 trials

\begin{tabular}{|c|c|c|c|}
\hline Taxonomic classification ${ }^{\mathrm{b}}$ & OTU code & CTR & $\mathrm{DIC}$ \\
\hline \multicolumn{4}{|l|}{ Salmonella trial } \\
\hline Bacteroidetes; Prevotellaceae; Prevotella & 300859 & 0.480 & 0.701 \\
\hline Firmicutes; Lachnospiraceae; Lachnospira & 349257 & 0.273 & 0.175 \\
\hline Firmicutes; Clostridiales & New ref. 2497 & 0.005 & 0.089 \\
\hline Unassigned & New ref. 6586 & 0.005 & 0.062 \\
\hline Firmicutes; Erysipelotrichaceae & 225636 & 0.055 & 0.002 \\
\hline Bacteroidetes; cand. Barnesiellaceae & 315846 & 0.048 & 0.003 \\
\hline Bacteroidetes; Bacteroidaceae; Bacteroides ovatus & 535375 & 0.039 & 0.015 \\
\hline Bacteroidetes; cand. Paraprevotellaceae; cand. Prevotella & New ref. 6366 & 0.065 & 0.052 \\
\hline Firmicutes; Christensenellaceae & 410242 & 0.001 & 0.024 \\
\hline Spirochaetes; Sphaerochaetaceae; Sphaerochaeta & 1832447 & 0.003 & 0.017 \\
\hline Bacteroidetes; Bacteroidales & New ref. 2311 & 0.003 & 0.025 \\
\hline Firmicutes; Clostridiales & 357471 & 0.012 & 0.033 \\
\hline Bacteroidetes; Prevotellaceae; Prevotella stercorea & New ref. 1872 & 0.008 & 0.033 \\
\hline Bacteroidetes; Prevotellaceae; Prevotella & New ref. 1748 & 0.009 & 0.022 \\
\hline Bacteroidetes; Prevotellaceae; Prevotella & 296082 & 0.008 & 0.023 \\
\hline Firmicutes; Lachnospiraceae; Lachnobacterium & 584463 & 0.017 & 0.001 \\
\hline Bacteroidetes; Prevotellaceae; Prevotella stercorea & New ref. 2808 & 0.001 & 0.008 \\
\hline Bacteroidetes; cand. Paraprevotellaceae; cand. Prevotella & New ref. 648 & 0.002 & 0.009 \\
\hline Bacteroidetes; Prevotellaceae; Prevotella stercorea & 302538 & 0.025 & 0.021 \\
\hline Firmicutes; Lachnospiraceae; Blautia & 526773 & 0.014 & 0.013 \\
\hline \multicolumn{4}{|l|}{ ETEC trial } \\
\hline Bacteroidetes; Prevotellaceae; Prevotella stercorea & 524371 & 2.430 & 1.654 \\
\hline Firmicutes; Clostridiales & 584083 & 0.210 & 0.261 \\
\hline Firmicutes; Veillonellaceae; Megasphaera & 298050 & 0.038 & 0.220 \\
\hline Firmicutes; Lachnospiraceae; Coprococcus & 344804 & 0.032 & 0.318 \\
\hline Firmicutes; Veillonellaceae; Dialister & 403701 & 0.001 & 0.056 \\
\hline Bacteroidetes; Bacteroidaceae; Bacteroides & 513445 & 0.006 & 0.084 \\
\hline Bacteroidetes; Prevotellaceae; Prevotella & 248447 & 0.049 & 0.046 \\
\hline Bacteroidetes; S24-7 & 844589 & 0.004 & 0.040 \\
\hline Bacteroidetes; Bacteroidales; cand. Paraprevotellaceae; YRC22 & 289468 & 0.034 & 0.030 \\
\hline Bacteroidetes; Prevotellaceae; Prevotella & New ref. 2220 & 0.021 & 0.014 \\
\hline Firmicutes; Erysipelotrichaceae & 287798 & 0.026 & 0.026 \\
\hline Firmicutes; Veillonellaceae; Megasphaera & 264967 & 0.017 & 0.011 \\
\hline Bacteroidetes; cand. Paraprevotellaceae; cand. Prevotella & New ref. 5084 & 0.008 & 0.004 \\
\hline Firmicutes; Clostridiales & 798164 & 0.010 & 0.011 \\
\hline Firmicutes; Ruminococcaceae & 583134 & 0.008 & 0.013 \\
\hline Firmicutes; Lachnospiraceae; Lachnospira & 843553 & 0.399 & 0.140 \\
\hline Firmicutes; Lachnospiraceae; Coprococcus & 366623 & 0.282 & 0.000 \\
\hline Firmicutes; Clostridiales & 826624 & 0.143 & 0.081 \\
\hline
\end{tabular}

${ }^{a}$ Mean relative abundances (\%) are presented for OTUs with an adjusted $P$ value $<0.05$ and detected in at least half of the animals per diet

${ }^{\mathrm{b}}$ Order is specified only when it represents the lowest rank classification 
$(P=0.069)$ compared to CTR animals. Other bacteria were numerically altered $(P<0.20)$ by DIC, with most of them representing $<1 \%$, with the exception of Veillonellaceae $(P=0.136$; approximately $15 \%)$ and the genus within Megasphaera $(P=0.149$; approximately $5 \%)$.

\section{Intestinal fermentation products}

Table 7 shows the modifications of the $\mathrm{pH}$ and the main fermentation products in the ileum and colon digesta for both trials. The ileal $\mathrm{pH}$ was not significantly modified by the experimental treatments, except for a numerical reduction (7.00 vs. $7.20 ; P=0.11)$ observed for DIC compared to CTR on d 4 PI in the Salmonella trial. In the ileum, the major product of fermentation was lactic acid, with ranges of 1.80-117 and 1.98-105 $\mu \mathrm{mol} / \mathrm{g}$ FM in Trial 1 and 2, respectively. No differences were detected between the diets. Acetic acid was found at very low levels in the ileum in both trials (average values of 1.61 and $4.44 \mu \mathrm{mol} / \mathrm{g}$ FM for Trial 1 and 2, respectively), with several animals below the minimum detection level on d 8 PI (12 for Trial 1 and 3 for Trial 2), and no differences between the experimental diets.

Regarding the colon digesta, there were no obvious changes in $\mathrm{pH}$, despite a slight reduction with DIC on $\mathrm{d} 4$ $\mathrm{PI}$ in the Salmonella trial (6.70 vs. $6.92 ; P=0.14$ ). The ammonia content was also not modified by the experimental diets. The total SCFA content was not modified by the experimental diets, but showed an increase from d 4 to 8 PI in both trials (from 92.7 to 141 and 104 to $159 \mu \mathrm{mol} / \mathrm{g}$ FM, respectively). The fermentation profile showed few changes with the diets; a numerical trend was observed in the Salmonella trial $(P=0.12)$ for an increase in the valeric acid proportion in the colon with DIC detected on $\mathrm{d} 4$ PI. In the ETEC trial, higher valeric concentrations were also observed with DIC supplementation than with CTR diets on $\mathrm{d} 8$ PI $(P=0.03)$.

\section{Ileal histomorphometry}

Table 8 shows the changes promoted by the experimental diet in terms of ileal histomorphometry. The villus height showed a marked increase from $\mathrm{d} 4$ to $8 \mathrm{PI}$ in both trials, but was not modified by the experimental diets, neither were the crypt depth or the villus:crypt ratio. There were no differences related to the inclusion of DIC either for the number of mitoses or the number of goblet cells. However, intriguingly, the IEL counts displayed a trend to decrease with DIC in the Salmonella trial on d 8 PI $(P=0.07)$, whereas these were increased $(P=0.08)$ with the additive in the ETEC F4 trial.

\section{Discussion}

The present study aimed to evaluate the possible antimicrobial effect of a mixture of medium-chain fatty acids
Table 7 Effects of the experimental diets on intestinal fermentation parameters in the Salmonella and ETEC F4 trials

\begin{tabular}{|c|c|c|c|c|c|c|c|c|}
\hline \multirow[t]{2}{*}{ Items } & \multicolumn{4}{|c|}{ Salmonella Trial } & \multicolumn{4}{|c|}{ ETEC F4 Trial } \\
\hline & $\overline{C T R}$ & $\mathrm{DIC}$ & RSE & $P$ & $\overline{\mathrm{CTR}}$ & $\mathrm{DIC}$ & RSE & $P$ \\
\hline \multicolumn{9}{|c|}{ lleum digesta } \\
\hline \multicolumn{9}{|l|}{$\mathrm{pH}$} \\
\hline $4 \mathrm{Pl}$ & 7.20 & 7.00 & 0.228 & 0.111 & 6.81 & 6.80 & 0.208 & 0.891 \\
\hline $8 \mathrm{Pl}$ & 7.37 & 7.34 & 0.190 & 0.786 & 6.86 & 6.77 & 0.195 & 0.346 \\
\hline \multicolumn{9}{|c|}{$\mathrm{NH}_{3}, \mu \mathrm{mol} / \mathrm{g}$} \\
\hline $4 \mathrm{Pl}$ & 4.4 & 2.0 & 2.77 & 0.113 & 0.6 & 1.4 & 1.91 & 0.431 \\
\hline $8 \mathrm{Pl}$ & 14.6 & 19.1 & 8.89 & 0.326 & 1.0 & 1.1 & 0.39 & 0.752 \\
\hline \multicolumn{9}{|c|}{ Lactic acid, $\mu \mathrm{mol} / \mathrm{g}$} \\
\hline $4 \mathrm{Pl}$ & 10.5 & 29.8 & 29.17 & 0.207 & 23.2 & 27.7 & 18.91 & 0.652 \\
\hline $8 \mathrm{Pl}$ & 41.8 & 23.4 & 27.09 & 0.196 & 19.1 & 36.0 & 25.73 & 0.209 \\
\hline \multicolumn{9}{|c|}{ Colon digesta } \\
\hline \multicolumn{9}{|l|}{$\mathrm{pH}$} \\
\hline $4 \mathrm{Pl}$ & 6.93 & 6.70 & 0.274 & 0.137 & 6.26 & 6.37 & 0.238 & 0.360 \\
\hline $8 \mathrm{Pl}$ & 7.07 & 7.04 & 0.156 & 0.671 & 5.97 & 6.07 & 0.266 & 0.464 \\
\hline \multicolumn{9}{|c|}{$\mathrm{NH}_{3}, \mu \mathrm{mol} / \mathrm{g}$} \\
\hline $4 \mathrm{Pl}$ & 32.5 & 24.4 & 19.94 & 0.431 & 10.7 & 10.8 & 5.821 & 0.969 \\
\hline $8 \mathrm{Pl}$ & 57.3 & 39.1 & 25.86 & 0.18 & 18.5 & 17.6 & 6.763 & 0.801 \\
\hline \multicolumn{9}{|c|}{ Total SCFA, $\mu \mathrm{mol} / \mathrm{g}$} \\
\hline $4 \mathrm{Pl}$ & 98 & 88 & 37.1 & 0.613 & 107 & 102 & 21.5 & 0.606 \\
\hline $8 \mathrm{Pl}$ & 147 & 136 & 17.6 & 0.244 & 155 & 163 & 21.5 & 0.461 \\
\hline \multicolumn{9}{|c|}{ Acetic acid, \% } \\
\hline $4 \mathrm{Pl}$ & 55.8 & 55.2 & 8.22 & 0.892 & 60.5 & 60.1 & 6.01 & 0.907 \\
\hline $8 \mathrm{Pl}$ & 56.0 & 54.2 & 7.37 & 0.629 & 61.3 & 60.2 & 4.06 & 0.573 \\
\hline \multicolumn{9}{|c|}{ Propionic acid, \% } \\
\hline $4 \mathrm{Pl}$ & 26.6 & 24.6 & 3.86 & 0.317 & 22.5 & 24.7 & 5.91 & 0.479 \\
\hline $8 \mathrm{Pl}$ & 21.7 & 25.9 & 6.52 & 0.218 & 22.6 & 23.1 & 3.32 & 0.778 \\
\hline \multicolumn{9}{|c|}{ Butyric acid, \% } \\
\hline $4 \mathrm{Pl}$ & 12.9 & 14.3 & 6.01 & 0.649 & 12.6 & 11.2 & 3.78 & 0.492 \\
\hline $8 \mathrm{Pl}$ & 17.0 & 15.3 & 3.61 & 0.373 & 13.5 & 12.7 & 2.09 & 0.452 \\
\hline \multicolumn{9}{|c|}{ Valeric acid, $\%$} \\
\hline $4 \mathrm{Pl}$ & 2.65 & 4.10 & 1.804 & 0.118 & 2.73 & 2.55 & 1.327 & 0.802 \\
\hline $8 \mathrm{Pl}$ & 4.10 & 3.53 & 1.467 & 0.456 & 1.59 & 2.84 & 1.056 & 0.033 \\
\hline \multicolumn{9}{|c|}{ BCFA, \% } \\
\hline $4 \mathrm{Pl}$ & 2.16 & 1.83 & 1.186 & 0.586 & 1.68 & 1.37 & 0.774 & 0.465 \\
\hline $8 \mathrm{Pl}$ & 1.27 & 1.11 & 0.531 & 0.566 & 0.95 & 1.21 & 0.365 & 0.176 \\
\hline
\end{tabular}

BCFA Branched-chain fatty acids, PI Post-inoculation day, RSE Residual standard error, SCFA Short-chain fatty acids

(MCFA) salts from coconut distillates (DIC) against enteric pathogens, such as Salmonella Typhimurium or ETEC F4, and the consequent reinforcement of the gut health and general health status of early-life weaned piglets. In order to fulfill these objectives, DIC was administered in feed in two different trials, each with one of the two pathogens. In both trials, animals exhibited signs of diarrhea after the oral challenge and an immediate decrease in feed intake. 
Table 8 Effects of the experimental diets on histomorphometry in the ileum in the Salmonella and ETEC F4 trials

\begin{tabular}{|c|c|c|c|c|c|c|c|c|}
\hline \multirow[t]{2}{*}{ Items } & \multicolumn{4}{|c|}{ Salmonella trial } & \multicolumn{4}{|c|}{ ETEC F4 trial } \\
\hline & CTR & DIC & RSE & $P$ & CTR & $\mathrm{DIC}$ & RSE & $P$ \\
\hline \multicolumn{9}{|c|}{ Villus height, $\mu \mathrm{m}$} \\
\hline $4 \mathrm{PI}$ & 185 & 183 & 65.5 & 0.962 & 278 & 229 & 89.4 & 0.289 \\
\hline $8 \mathrm{PI}$ & 282 & 276 & 58.1 & 0.852 & 323 & 321 & 63.7 & 0.955 \\
\hline \multicolumn{9}{|c|}{ Crypt depth, $\mu \mathrm{m}$} \\
\hline $4 \mathrm{PI}$ & 315 & 323 & 69.6 & 0.815 & 196 & 182 & 30.9 & 0.38 \\
\hline $8 \mathrm{PI}$ & 300 & 290 & 37.1 & 0.596 & 189 & 184 & 19.7 & 0.600 \\
\hline \multicolumn{9}{|c|}{ Villus:Crypt } \\
\hline $4 \mathrm{PI}$ & 0.60 & 0.63 & 0.257 & 0.841 & 1.47 & 1.29 & 0.469 & 0.454 \\
\hline $8 \mathrm{PI}$ & 0.99 & 0.99 & 0.209 & 0.944 & 1.78 & 1.79 & 0.364 & 0.935 \\
\hline \multicolumn{9}{|c|}{ MIT, cells/100 $\mu \mathrm{m}$} \\
\hline $4 \mathrm{PI}$ & 0.251 & 0.325 & 0.160 & 0.39 & 0.078 & 0.068 & 0.103 & 0.845 \\
\hline $8 \mathrm{PI}$ & 0.075 & 0.099 & 0.082 & 0.569 & 0.104 & 0.091 & 0.141 & 0.862 \\
\hline \multicolumn{9}{|c|}{ GC, cells/100 $\mu \mathrm{m}$} \\
\hline $4 \mathrm{PI}$ & 2.20 & 1.93 & 0.851 & 0.556 & 1.75 & 1.43 & 0.542 & 0.262 \\
\hline $8 \mathrm{PI}$ & 1.49 & 1.28 & 0.548 & 0.457 & 1.31 & 1.33 & 0.519 & 0.954 \\
\hline \multicolumn{9}{|c|}{ IEL, cells/100 $\mu \mathrm{m}$} \\
\hline $4 \mathrm{PI}$ & 2.92 & 2.76 & 1.509 & 0.841 & 2.07 & 2.04 & 0.482 & 0.917 \\
\hline $8 \mathrm{PI}$ & 3.92 & 3.06 & 0.882 & 0.072 & 2.39 & 2.88 & 0.523 & 0.080 \\
\hline
\end{tabular}

GC Goblet cells in the villus, IEL Intraepithelial lymphocytes in the villus, MIT Mitoses in the crypt, PI Post-inoculation day, RSE Residual standard error

During the week of adaptation after weaning, animals from the different diets displayed similar performances, with no influence of DIC supplementation. Other authors, however, have described improvements in performance related to the supplementation of MCFA. Some works evaluating MCFA as an energy source, at higher doses (2.1-7.75\%), registered growth improvements $[6,13,46,47]$ that could be justified by the more rapid digestion and absorption of these fatty acids. Improvements have also been seen in animals challenged with ETEC F4 or LPS [23, 48], however, not necessarily by using high doses. Regarding the possible effects of MCFA supplementation on feed intake, we did not detect any impact of the experimental diets. The potential impact of MCFA as additives on feed intake is controversial. When supplemented at high levels, as a rapid source of energy, MCFA could prompt satiety due to their rapid oxidation in the liver $[49,50]$. Moreover, MCFA have also been described as rancid and presenting low palatability $[51,52]$, which could therefore lead to a decline in feed intake and impair the adaptation to dry feed after weaning. Nonetheless, in our study, there was no negative impact of DIC on the feed intake during the first week post-weaning. The lower dosage (at $0.3 \%)$ than that used in other studies, and the different nature and composition of MCFA blends, could explain the discrepancies with other studies.
One of the most remarkable effects of this study was the specific action of supplemented MCFA on populations of Salmonella, coliforms, and enterobacteria. Salmonella spp. counts in the cecum tended to be reduced by DIC, despite a higher initial colonization after the challenge. After the ETEC F4 inoculation, DIC consistently diminished the enterobacteria and total coliform populations in the luminal content of the ileum and colon (particularly on $\mathrm{d} 8 \mathrm{PI}$ ), and the same trend was observed in the ileal mucosa, despite the effects on the luminal E. coli $\mathrm{F} 4$ pathogen being small. As stated in the introduction, a higher antibacterial activity has been described for MCFA than other free fatty acids [53]. Most recent studies have demonstrated their in vitro activity against a wide range of pathogenic bacteria $[5,11$, 53, 54]. Lauric acid (C12) has been shown to have the highest antimicrobial activity among the fatty acids present in coconut oil $[54,55]$. However, other mediumchain fatty acids, caprylic acid (C8) and capric acid (C10), showed the highest antimicrobial activity against different E. coli and Salmonella strains tested [3]. Freese et al. [56] and Sheu et al. [57] also reported lower minimum inhibitory concentrations (MIC) of caproic (C6) and caprylic (C8) acids for $50 \%$ growth inhibition of $E$. coli than capric acid (C10) and C12. Furthermore, C6 and $\mathrm{C} 8$ have been selected for their antimicrobial activity, rather than longer-chain fatty acids, to be tested in in vivo trials [23]. Nevertheless, although $\mathrm{C} 12$ is the major compound in the distillates of coconut $(48.4 \%$ crude fat, $\mathrm{CF}$ ), these also include important proportions of other MCFA (6.2\% CF for C8 and 5.8\% CF for C10) that might support the aforementioned effects.

Among the in vivo studies that have evaluated the effect of MCFA administration on pathogens, some authors have described lower numbers of clostridia or $E$. coli $[15,16,58-60]$, and also Salmonella [22]. These reported effects on the colonization of the gut by different pathogens could have been mediated by the direct activity of MCFA, but also indirectly, by changes promoted by these additives in the intestinal microbiota. In this regard, different in vivo trials in pigs have described significant changes in bacterial populations promoted by the direct supplementation of MCFA supplementation $[61,62]$, including a transgenerational influence observed by the supplementation of sows having an effect on their offspring [63]. The variability in these effects in the literature could be the result of differences between MCFA sources, blends, dosages, and methods of administration, making the direct comparison between studies difficult. In particular, most of the experimental blends tested were composed of a combination of C8 and C10 and negligible quantities of $\mathrm{C} 12$, or their conjugated forms, into triacylglycerol (MCT), with lipases needed to release, not always successfully, the free fatty acids. 
To our knowledge, very few works have evaluated the effect of MCFA on intestinal microbiota by performing an entire profiling of their populations, particularly when faced with a pathogen challenge. The results of our work show that, in global terms, the microbiota profiles observed after the two challenges were not substantially different from those previously described for piglets of this age [64, 65], suggesting that these animals did not suffer any drastic dysbiosis. In fact, other challenges in piglets with Salmonella could not differentiate clusters from unchallenged and Salmonella-challenged animals either [66], and were not even able to detect the Salmonella genus by HTS, as occurred in our animals. Nevertheless, it must be taken into account that the activity of the supplemented MCFA against potential pathogens was observed mainly in the ileum and cecum, and the assortment of microbial populations was also affected. This leads us to hypothesize that the direct impact on upper parts of the gut is reflected, for instance, on the gastric barrier or the small intestine in the foregut.

Nevertheless, there were still observed microbiota changes promoted by DIC diets. In both trials, the DIC diets were able to significantly modify particular microbial taxa, although the affected bacterial groups were different. With the Salmonella challenge, the most relevant change was a significant increase registered in the Fibrobacteres phylum $(P=0.019)$. Accompanied by a (numerical) reduction in Enterobacteriaceae, it could be hypothesized that the supplemented MCFA prompts a more fibrolytic-like adult microbial profile. In addition, it is interesting to remark that several OTUs from the Lachnospiraceae family were decreased with the DIC diet compared to the CTR diet and that the Lachnospira genus has been reported to increase with the presence of Salmonella [67]. This response of the microbiota to DIC supplementation could also be associated with the response registered in IEL at the ileal level. On d 8 PI, the animals treated with DIC and challenged with Salmonella maintained lower numbers of IEL than the CTR group. A possible hypothesis is that the pigs in the DIC group might have retained a more benign environment within the gastrointestinal tract. Another plausible explanation could be that the clear reduction in the pathogen counts in the cecum by the addition of DIC stopped the recruitment of IELs, since these defense cells have been found near Salmonella pathogens [68]. In fact, the IEL counts were higher within the Salmonella challenge than in previous trials in our group [33, 69], reflecting a more acute course of diarrhea. If we consider that the IELs remain quiescent until facing a real threat [70], it seems reasonable that after the Salmonella challenge, DIC treatment had the opportunity to show its effects on the current IEL response.

However, within the ETEC F4 trial, the reduction in possible specific commensal populations such as enterobacteria and coliforms as observed in the ETEC F4challenged animals, might suggest a more hostile milieu, which consequently mobilized more IELs than the CTR group. In turn, the IEL response could also be related to a possible readaptation of the community structure, as seen in the NMDS results (envfit $P=0.035$ ). In this regard, the impact of the MCFA supplementation was evident at the structural level, with the most relevant change in the bacterial groups observed for the increase in Dialister $(P=0.008)$ within the Veillonellaceae family. However, other mechanisms related to a direct modulator effect of MCFA on the immune response of the animal should not be disregarded. MCFA supplemented to pre-weaning piglets as triglycerides (MCT) have been shown to stimulate the immune response in the stomach, regardless of the complexity of the microbiota [71]. In addition, similar stimulatory effects on intestinal villi and the local immunity have been demonstrated in LPSchallenged weanlings based on C6- and C8-MCT [23].

To try and elucidate possible associations between the microbial populations and gut variables assessed in this study, particularly those modified by the experimental treatments, we performed a correlation analysis; the most relevant correlations $(r>0.5$ and adjusted $P<$ 0.10) are presented in Table 9. Interestingly, candidate Barnesiellaceae and Enterobacteriaceae families were positively correlated with the IEL counts in the Salmonella trial, whereas in the ETEC F4 trial, no significant correlation was found. This could be somehow related to the differential response registered in IEL with DIC between both trials. Valeric acid showed only a significant high inverse correlation with Clostridiaceae $(P=$ 0.011) in the Salmonella trial. Under the ETEC F4

Table 9 Pearson's correlations ${ }^{\mathrm{a}}$ between gut variables and bacterial populations for Salmonella and ETEC F4 trials

\begin{tabular}{clll}
\hline Gut variable & Microbiota $^{\text {b }}$ & Pearson $(r)$ & Adjusted $P$ \\
\hline Salmonella trial & & & \\
IEL & candidate Barnesiellaceae & 0.698 & 0.055 \\
IEL & candidate Odoribacteraceae & 0.694 & 0.057 \\
IEL & Odoribacter & 0.694 & 0.057 \\
IEL & Enterobacteriaceae & 0.686 & 0.065 \\
Valeric acid & Clostridiaceae & -0.782 & 0.011 \\
ETEC F4 trial & & & \\
Valeric acid & Megasphaera & 0.837 & 0.005 \\
Valeric acid & Veillonellaceae & 0.784 & 0.023 \\
\hline
\end{tabular}

IEL Intraepithelial lymphocytes in the ileal villus

${ }^{a}$ Correlations considered: $r>0.5$ and adjusted $P<0.10$

${ }^{\mathrm{b}}$ Microbial populations identified by high-throughput sequencing (HTS) 
challenge, valeric acid was positively correlated with Megasphaera $(r=0.837)$ and the corresponding family Veillonellaceae $(r=0.784)$. This correlation is coincident with the higher presence of Dialister on d 8 PI in DIC animals and the higher percentage of valeric acid than in CTR animals. Dialister and Megasphaera, among other members within the Veillonellaceae family, have been reported to produce valeric acid as an end metabolite of the fermentation of carbohydrates and lactate [72].

\section{Conclusions}

The results obtained from this study support the activity of a blend of sodium salts of coconut oil distillates in reducing the hindgut colonization by pathogenic populations such as enterobacteria, E. coli, and Salmonella in orally-challenged weaned piglets. The effects could be mediated by the changes promoted in the microbiota ecosystem since significant effects were registered in different microbial groups. Under a Salmonella challenge, significant increases were registered in the Fibrobacteres phylum and after an ETEC F4 challenge, the most relevant changes were registered in the Dialister genus of the Veillonellaceae family within a diverging microbial structure. There was also a differential impact of this blend on the intestinal local immune response, leading to higher numbers of ileal intraepithelial lymphocytes after the Salmonella challenge, but lower numbers after the ETEC F4 challenge. The effects of the supplemented MCFA might respond to different complex interactions between the opportunistic pathogens, the commensal microbiota and the host response.

\section{Abbreviations \\ ADFI: Average daily feed intake; ADG: Average daily gain; ANOSIM: Analysis of similarities; BW: Body weight; CFU: Colony-forming unit; DM: Dry matter; ETEC: Enterotoxigenic Escherichia coli; FM: Fresh matter; GC: Goblet cells; HTS: High-throughput sequencing; IEL: Intraepithelial lymphocytes; MCFA: Medium-chain fatty acids; MCT: Medium-chain triglycerides; MIT: Mitoses; OTU: Operational taxonomic unit; PBS: Phosphate buffered solution; PI: Post-inoculation; Prel: Pre-inoculation; qPCR: Quantitative polymerase-chain reaction; SCFA: Short-chain fatty acids}

\section{Acknowledgments}

The authors would like to thank Laura Noguera Solans for her support with the experimental trial.

\section{Authors' contributions}

LC, MP, JJM, and SMMO conceived and designed the experiments; MP and JJM contributed reagents and materials; PLC and ARS performed the experiment and the laboratory analyses; PLC received, curated, and maintained the animal records; LC and SMMO supervised the experiment; PLC, LC, and SMMO analyzed and interpreted the data and wrote the paper. All authors read and approved the final manuscript.

\section{Funding}

This work was funded by the "PORCDIGEST" project (IDI-20140262), funded by the CDTI and the Ministerio de Economía y Competitividad (Spain) and had support from the pre-doctoral FI grant of the Generalitat de Catalunya (Spain) awarded to Paola López-Colom.

\section{Availability of data and materials}

The datasets used and analyzed during the current study are available from the corresponding author on reasonable request. The dataset generated corresponding to the final 16S rRNA gene sequences is available in the European Nucleotide Archive (ENA), accession code PRJEB30494.

\section{Ethics approval and consent to participate}

All procedures with animals received prior approval from the Animal and Human Experimental Ethical Committee of the UAB (permit no. CEAAH 2933)

Consent for publication

Not applicable.

\section{Competing interests}

The authors declare that they have no competing interests.

\section{Author details}

${ }^{1}$ Animal Nutrition and Welfare Service, Animal and Food Science Department, Facultat de Veterinària, Universitat Autònoma de Barcelona, Bellaterra, Spain. ${ }^{2}$ Norel S.A, Madrid, Spain.

Received: 20 April 2019 Accepted: 6 September 2019

Published online: 09 November 2019

\section{References}

1. EFSA, ECDC. The European Union summary report on antimicrobial resistance in zoonotic and indicator bacteria from humans, animals and food in 2015. EFSA J. 2017;15:4694.

2. Heo JM, Opapeju FO, Pluske JR, Kim JC, Hampson DJ, Nyachoti CM. Gastrointestinal health and function in weaned pigs: a review of feeding strategies to control post-weaning diarrhoea without using in-feed antimicrobial compounds. J Anim Physiol Anim Nutr. 2012;97(2):207-37.

3. Skrivanová E, Marounek M, Benda V, Brezina P. Susceptibility of Escherichia coli, Salmonella sp. and Clostridium perfringens to organic acids and monolaurin. Vete Med. 2006;51(3):81-8.

4. Petschow BW, Batema RP, Ford LL. Susceptibility of Helicobacter pylori to bactericidal properties of medium-chain monoglycerides and free fatty acids. Antimicrob Agents Chemother. 1996;40(2):302-6.

5. Manohar V, Echard B, Perricone N, Ingram C, Enig M, Bagchi D, et al. In vitro and in vivo effects of two coconut oils in comparison to monolaurin on Staphylococcus aureus: rodent studies. J Med Food. 2013;16(6):499-503.

6. Li Y, Zhang $H$, Yang L, Zhang L, Wang T. Effect of medium-chain triglycerides on growth performance, nutrient digestibility, plasma metabolites and antioxidant capacity in weanling pigs. Anim Nutr. 2015; 1(1):12-8.

7. Schönfeld $P$, Wojtczak L. Short- and medium-chain fatty acids in energy metabolism: the cellular perspective. J Lipid Res. 2016;57(6):943-54.

8. DebMandal M, Mandal S. Coconut (Cocos nucifera L.: Arecaceae): in health promotion and disease prevention. Asian Pac J Trop Med. 2011;4(3):241-7.

9. Baltić B, Starčević M, Đorđević J, Mrdović B, Marković R. Importance of medium chain fatty acids in animal nutrition. In: IOP Conf Ser Earth Environ Sci, vol. 85; 2017.

10. Zentek J, Buchheit-Renko S, Ferrara F, Vahjen W, Van Kessel AG, Pieper R. Nutritional and physiological role of medium-chain triglycerides and medium-chain fatty acids in piglets. Anim Health Res Rev. 2011;12(1):83-93.

11. Vande Maele L, Heyndrickx M, Maes D, De Pauw N, Mahu M, Verlinden M, et al. In vitro susceptibility of Brachyspira hyodysenteriae to organic acids and essential oil components. J Vet Med Sci. 2016;78(2):325-8.

12. Hernández A, Pluske J. Using dietary medium-chain triglycerides to improve post-weaning performance of pigs. Pork CRC 2B-102/103-0506. 2008. url: http://researchrepository.murdoch.edu.au/id/eprint/30626. Accessed Nov 2017

13. Weng RC. Dietary fat preference and effects on performance of piglets at weaning. Asian-Australas J Anim Sci. 2017;30(6):834-42

14. Dierick NA, Decuypere JA, Molly K, Van Beek E, Vanderbeke E. The combined use of triacylglycerols (TAGs) containing medium chain fatty acids (MCFAs) and exogenous lipolytic enzymes as an alternative for nutritional antibiotics in piglet nutrition. II. In vivo release of MCFAs in gastric cannulated and slaughtered piglets by endogenous and exogenous 
lipases; effects on the luminal gut flora and growth performance. Livest Prod Sci. 2002;76(1-2):1-16.

15. Hanczakowska E, Szewczyk A, Okoń K. Effects of dietary caprylic and capric acid on piglet performance and mucosal epithelium structure of ileum. J Anim Feed Sci. 2011;20:556-65.

16. Kuang $Y$, Wang $Y$, Zhang $Y$, Song $Y$, Zhang $X$, Lin $Y$, et al. Effects of dietary combinations of organic acids and medium chain fatty acids as a replacement of zinc oxide on growth, digestibility and immunity of weaned pigs. Anim Feed Sci Technol. 2015;208:145-57.

17. Dierick NA, Decuypere JA, Molly K, Van Beek E, Vanderbeke E. The combined use of triacylglycerols containing medium-chain fatty acids (MCFAs) and exogenous lipolytic enzymes as an alternative for nutritional antibiotics in piglet nutrition. I. In vitro screening of the release of MCFAs from selected fat sources by selected exogenous lipolytic enzymes under simulated pig gastric conditions and their effects on the gut flora of piglets. Livest Prod Sci. 2002;75(2):129-42.

18. Messens W, Goris J, Dierick N, Herman L, Heyndrickx M. Inhibition of Salmonella typhimurium by medium-chain fatty acids in an in vitro simulation of the porcine cecum. Vet Microbiol. 2010;141(1-2):73-80.

19. Martínez-Vallespín B, Vahjen W, Zentek J. Effects of medium-chain fatty acids on the structure and immune response of IPEC-J2 cells. Cytotechnology. 2016;68(5):1925-36.

20. Kono H, Fujii H, Asakawa M, Maki A, Amemiya H, Hirai Y, et al. Medium-chain triglycerides enhance secretory IgA expression in rat intestine after administration of endotoxin. Am J Physiol Gastrointest Liver Physiol. 2004;286(6):G1081-9.

21. Van Immerseel F, De Buck J, Boyen F, Bohez L, Pasmans F, Volf J, et al. Medium-chain fatty acids decrease colonization and invasion through hilA suppression shortly after infection of chickens with Salmonella enterica serovar Enteritidis. Appl Environ Microbiol. 2004;70:3582-7.

22. Rasschaert G, Michiels J, Tagliabue M, Missotten J, De Smet S, Heyndrickx M. Effect of organic acids on Salmonella shedding and colonization in pigs on a farm with high Salmonella prevalence. J Food Prot. 2016;79(1):51-8.

23. De Keyser K, Dierick N, Kanto U, Hongsapak T, Buyens G, Kuterna L, et al. Medium-chain glycerides affect gut morphology, immune- and goblet cells in post-weaning piglets: in vitro fatty acid screening with Escherichia coli and in vivo consolidation with LPS challenge. J Anim Physiol Anim Nutr. 2019:103:221-30.

24. NRC. Nutrient requirements of swine: eleventh revised edition. 11th ed. Washington: The National Academies Press; 2012.

25. AOAC. Official methods of analysis. 18th ed. Gaithersburg: Association of Official Analytical Chemists; 2007.

26. Van Soest PJ, Robertson JB, Lewis BA. Methods for dietary fiber, neutral detergent fiber, and nonstarch polysaccharides in relation to animal nutrition. J Dairy Sci. 1991;74(10):3583-97.

27. Gustavo Hermes R, Molist F, Pérez JF, Gómez de Segura A, Ywazaki M, Davin $\mathrm{R}$, et al. Casein glycomacropeptide in the diet may reduce Escherichia coli attachment to the intestinal mucosa and increase the intestinal lactobacill of early weaned piglets after an enterotoxigenic $E$. coli K88 challenge. Br J Nutr. 2013;109(6):1001-12.

28. Caporaso JG, Kuczynski J, Stombaugh J, Bittinger K, Bushman FD, Costello EK, et al. QIIME allows analysis of high-throughput community sequencing data. Nat Methods. 2010;7(5):335-6

29. Rideout JR, He Y, Navas-Molinas JA, Walters WA, Ursell LK, Gibbons SM, et al. Subsampled open-reference clustering creates consistent, comprehensive OTU definitions and scales to billions of sequences. PeerJ. 2014;2:e545.

30. DeSantis TZ, Hugenholtz P, Larsen N, Rojas M, Brodie EL, Keller K, et al, Greengenes, a chimera-checked 16s rRNA gene database and workbench compatible with ARB. Appl Environ Microbiol. 2006;72:5069-72.

31. Haas BJ, Gevers D, Earl AM, Feldgarden M, Ward DV, Giannoukos G, et al. Chimeric 165 rRNA sequence formation and detection in Sanger and 454pyrosequenced PCR amplicons. Genome Res. 2011;21(3):494-504.

32. Bokulich NA, Subramanian S, Faith JJ, Gevers D, Gordon Jl, Knight R, et al. Quality-filtering vastly improves diversity estimates from Illumina amplicon sequencing. Nat Methods. 2013;10(1):57-9.

33. Barba-Vidal E, Buttow Roll VF, Castillejos L, Guerra-Ordaz AA, Manteca X, Mallo JJ, Martín-Orúe SM. Response to a Salmonella Typhimurium challenge in piglets supplemented with protected sodium butyrate or Bacillus licheniformis: effects on performance, intestinal health and behavior. Transl Anim Sci. 2017;1(2):186-200.

34. Richardson AJ, Calder AG, Stewart CS, Smith A. Simultaneous determination of volatile and non-volatile acidic fermentation products of anaerobes by capillary gas chromatography. Lett Appl Microbiol. 1989;9(1):5-8.
35. Jensen MT, Cox RP, Jensen BB. Microbial production of skatole in the hind gut of pigs given different diets and its relation to skatole deposition in backfat. Anim Sci. 1995;61(2):293-304.

36. Nofrarías M, Manzanilla EG, Pujols J, Gibert X, Majó N, Segalés J, et al. Effects of spray-dried porcine plasma and plant extracts on intestinal morphology and on leukocyte cell subsets of weaned pigs. J Anim Sci. 2006;84(10):2735-42.

37. R Core Team. R: a language and environment for statistical computing. Vienna: R Foundation for Statistical Computing; 2013.

38. Piñeiro C, Piñeiro M, Morales J, Andrés M, Lorenzo E, Pozo MD, et al. PigMAP and haptoglobin concentration reference values in swine from commercial farms. Vet J. 2009;179(1):78-84.

39. Douglas B, Mächler M, Bolker B, Walker S. Fitting linear mixed-effects models using Ime4. J Stat Softw. 2015;67(1):1-48.

40. McMurdie PJ, Holmes S. Phyloseq: an R package for reproducible interactive analysis and graphics of microbiome census data. PLoS One. 2013;8(4): e61217.

41. Oksanen J. vegan: community ecology package. 2009. https://cran.r-project. org/web/packages/vegan/vegan.pdf. Accessed May 2018.

42. Chao A. Nonparametric estimation of the number of classes in a population. Scand J Stat. 1984;11(4):265-70.

43. Shannon CE, Weaver W. The mathematical theory of communication. Urbana: University Illinois Press; 1963. p. 117.

44. Zeileis A, Kleiber C, Jackman S. Regression models for count data in R. J Stat Softw. 2008. https://doi.org/10.18637/jss.v027.08.

45. Venables WN, Ripley BD. Modern applied statistics with S. 4th ed. New York: Springer; 2002.

46. Cera KR, Mahan DC, Reinhart GA. Evaluation of various extracted vegetable oils, roasted soybeans, medium-chain triglyceride and an animal-vegetable fat blend for postweaning swine. J Anim Sci. 1990;68:2756-65.

47. Rodas BD, Maxwell CV. The effect of fat source and medium-chain triglyceride level on performance of the early-weaned pig. Anim Sci Res Rep. 1990;129(9):278-87.

48. Lei XJ, Park JW, Baek DH, Kim JK, Kim IH. Feeding the blend of organic acids and medium chain fatty acids reduces the diarrhea in piglets orally challenged with enterotoxigenic Escherichia coli K88. Anim Feed Sci Technol. 2017;224:46-51.

49. Guillot $E$, Vaugelade $P$, Lemarchal $P$, Rérat A. Intestinal absorption and liver uptake of medium-chain fatty acids in non-anaesthetized pigs. $\mathrm{Br} J$ Nutr. 1993;69:431-42.

50. Geng S, Zhu W, Xie X, Li X, Wu J, Liang Z, et al. Medium-chain triglyceride ameliorates insulin resistance and inflammation in high fat diet-induced obese mice. EurJ Nutr. 2016;55(3):931-40.

51. Decuypere JA, Dierick NA. The combined use of triacylglycerols containing medium-chain fatty acids and exogenous lipolytic enzymes as an alternative to in-feed antibiotics in piglets: concept, possibilities and limitations. An overview. Nutr Res Rev. 2003;16(2):193-210.

52. Desbois AP, Smith VJ. Antibacterial free fatty acids: activities, mechanisms of action and biotechnological potential. Appl Microbiol Biotechnol. 2009;85: $1629-42$.

53. Batovska DI, Todorova IT, Tsvetkova IV, Najdenski HM. Antibacterial study of the medium chain fatty acids and their 1-monoglycerides: Individual effects and synergistic relationships. Polish J Microbiol. 2009;58(1):43-7.

54. Shilling M, Matt L, Rubin E, Visitacion MP, Haller NA, Grey SF, et al. Antimicrobial effects of virgin coconut oil and its medium-chain fatty acids on Clostridium difficile. J Med Food. 2013;16(12):1079-85.

55. Tangwatcharin P, Khopaibool P. Activity of virgin coconut oil, lauric acid or monolaurin in combination with lactic acid against Staphylococcus aureus. Southeast Asian J Trop Med Public Health. 2012;43(4):969-85.

56. Freese E, Sheu C, Galliers E. Function of lipophilic acids as antimicrobial food additives. Nature. 1973;241:321-5.

57. Sheu C, Salomon D, Simmons J, Sreevalsan T, Freese E. Inhibitory effects of lipophilic acids and related compounds on bacteria and mammalian cells. Antimicrob Agents Chemother. 1975;7:349-63.

58. Dierick NA, Michiels J, Van Nevel C. Effect of medium chain fatty acids and benzoic acid, as alternatives for antibiotics, on growth and some gut parameters in piglets. Commun Agric Appl Biol Sci. 2004;69(2):187-90.

59. Upadhaya SD, Lee KY, Kim IH. Protected organic acid blends as an alternative to antibiotics in finishing pigs. Asian-Australasian J Anim Sci. 2014;27(11):1600-7.

60. Upadhaya SD, Lee KY, Serpunja S, Song TH, Kim IH. Growth performance, nutrient digestibility, fecal microbiota and fecal noxious gas emission in 
weaning pigs fed high and low density diet with and without protected organic acid blends. Anim Feed Sci Technol. 2018;239:1-8.

61. Zentek J, Buchheit-Renko S, Männer K, Vahjen W. Intestinal concentrations of free and encapsulated dietary medium-chain fatty acids and effects on gastric microbial ecology and bacterial metabolic products in the digestive tract of piglets. Arch Anim Nutr. 2012;66(1):14-26.

62. Zentek J, Ferrara F, Pieper R, Tedin L, Meyer W, Vahjen W. Effects of dietary combinations of organic acids and medium chain fatty acids on the gastrointestinal microbial ecology and bacterial metabolites in the digestive tract of weaning piglets. J Anim Sci. 2013;91(7):3200-10.

63. Lan R, Kim I. Effects of organic acid and medium chain fatty acid blends on the performance of sows and their piglets. Anim Sci J. 2018;89(12):1673-9.

64. Xiao L, Estellé J, Kiilerich P, Ramayo-Caldas Y, Xia Z, Feng Q, et al. A reference gene catalogue of the pig gut microbiome. Nat Microbiol. 2016; 19:16161.

65. Holman DB, Brunelle BW, Trachsel J, Allen HK. Meta-analysis to define a core microbiota in the swine gut. mSystems. 2017;2(3):e00004-17.

66. Borewicz KA, Kim HB, Singer RS, Gebhart CJ, Sreevatsan S, Johnson T, et al. Changes in the porcine intestinal microbiome in response to infection with Salmonella enterica and Lawsonia intracellularis. PLoS One. 2015;1010: e0139106.

67. Leite FLL, Singer RS, Ward T, Gebhart CJ, Isaacson RE. Vaccination against Lawsonia intracellularis decreases shedding of Salmonella enterica serovar Typhimurium in co-infected pigs and alters the gut microbiome. Sci Rep. 2018;8:2857.

68. Hoytema van Konijnenburg DP, Reis BS, Pedicord VA, Farache J, Victora GD, Mucida D. Intestinal epithelial and intraepithelial T cell crosstalk mediates a dynamic response to infection. Cell. 2017;171(4):783-94.

69. Barba-Vidal E, Castillejos L, Roll VFB, Cifuentes-Orjuela G, Moreno Muñoz JA, Martín-Orúe SM. The probiotic combination of Bifidobacterium longum subsp. infantis CECT 7210 and Bifidobacterium animalis subsp. lactis BPL6 reduces pathogen loads and improves gut health of weaned piglets orally challenged with Salmonella Typhimurium. Front Microbiol. 2017;8:1570.

70. Cheroutre H. IELs: enforcing law and order in the court of the intestinal epithelium. Immunol Rev. 2005;206:114-31.

71. Trevisi P, Priori D, Motta V, Luise D, Jansman AJM, Koopmans SJ, et al. The effects of starter microbiota and the early life feeding of medium chain triglycerides on the gastric transcriptome profile of 2- or 3-week-old cesarean delivered piglets. J Anim Sci Biotechnol. 2017;8:82.

72. Marchandin H, Teyssier C, Campos J, Jean-Pierre H, Roger F, Gay B, et al. Negativicoccus succinicivorans gen. nov., sp. nov., isolated from human clinical samples, emended description of the family Veillonellaceae and description of Negativicutes classis nov., Selenomonadales ord. nov. and Acidaminococcaceae fam. nov. In the bacterial phylum Firmicutes. Int J SystEvol Microbiol. 2010;60(6):1271-9.

Ready to submit your research? Choose BMC and benefit from:

- fast, convenient online submission

- thorough peer review by experienced researchers in your field

- rapid publication on acceptance

- support for research data, including large and complex data types

- gold Open Access which fosters wider collaboration and increased citations

- maximum visibility for your research: over $100 \mathrm{M}$ website views per year

At $\mathrm{BMC}$, research is always in progress.

Learn more biomedcentral.com/submissions 